\title{
Cold atmospheric plasma technology for removal of organic micropollutants from wastewater-a review
}

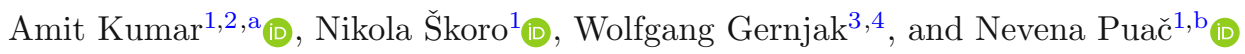 \\ 1 Institute of Physics, University of Belgrade, Pregrevica 118, 11080 Belgrade, Serbia \\ 2 Universitat de Girona, 17003 Girona, Spain \\ 3 Catalan Institute for Water Research (ICRA), 17003 Girona, Spain \\ ${ }^{4}$ Catalan Institution for Research and Advanced Studies (ICREA), 08010 Barcelona, Spain
}

Received 17 February 2021 / Accepted 1 October 2021 / Published online 2 November 2021 (C) The Author(s) 2021

\begin{abstract}
Water bodies are being contaminated daily due to industrial, agricultural and domestic effluents. In the last decades, harmful organic micropollutants (OMPs) have been detected in surface and groundwater at low concentrations due to the discharge of untreated effluent in natural water bodies. As a consequence, aquatic life and public health are endangered. Unfortunately, traditional water treatment methods are ineffective in the degradation of most OMPs. In recent years, advanced oxidation processes (AOPs) techniques have received extensive attention for the mineralization of OMPs in water in order to avoid serious environmental problems. Cold atmospheric plasma discharge-based AOPs have been proven a promising technology for the degradation of non-biodegradable organic substances like OMPs. This paper reviews a wide range of cold atmospheric plasma sources with their reactor configurations used for the degradation of OMPs (such as organic dyes, pharmaceuticals, and pesticides) in wastewater. The role of plasma and treatment parameters (e.g. input power, voltage, working gas, treatment time, OMPs concentrations, etc.) on the oxidation of various OMPs are discussed. Furthermore, the degradation kinetics, intermediates compounds formed by plasma, and the synergetic effect of plasma in combination with a catalyst are also reported in this review.
\end{abstract}

\section{Introduction}

Clean water is necessary to the ecosystem, to sustain life as well as social and economic development [1,2]. However, as the population is growing, the anthropogenic effect on the surrounding environment is increasing every day $[3,4]$. Nowadays, the wastewater generated from sources such as industry, agriculture, houses, and so on contains considerable amounts of organic micropollutants (OMPs) and thus causes many problems related to the environment and health $[3,5-7]$. According to several investigations, various OMPs such as pharmaceuticals, pesticides, organic dyes have been frequently detected in the wastewater, surface water, and even in drinking water (see Fig. 1) [5, 8-10].

Examples of frequently observed OMPs are listed in Table 1.

Many wastewater effluents contain a high level of contaminants due to a considerable number of OMPs being non-biodegradable. Thus, the degradation of OMPs in water became a major challenge $[5,10]$. Typical characteristics of wastewater from textile, pharmaceutical, and pesticide industries are presented in Table 2. According to the data, the higher ratio of COD to BOD

\footnotetext{
a e-mail: amit@ipb.ac.rs (corresponding author)

b e-mail: nevena@ipb.ac.rs
}

that appear in all three cases indicates that wastewater had an extremely high level of refractory organic substances. This kind of wastewater must be treated before releasing in nature in order to prevent harm to living beings and the environment.

The degradation of most OMPs in conventional wastewater treatment plants (e.g. using biological processes) is inefficient because of their complex and stable molecular structures. As a consequence, OMPs unaffected by the treatment are returned to the natural waters $[7,29,30]$. Recently, for the removal of OMPs from wastewater several advanced oxidation processes (AOPs) have been developed including $\mathrm{H}_{2} \mathrm{O}_{2}$ - Fenton, $\mathrm{UV} / \mathrm{TiO}_{2}, \mathrm{O}_{3} / \mathrm{H}_{2} \mathrm{O}_{2}, \mathrm{UV} / \mathrm{H}_{2} \mathrm{O}_{2}, \mathrm{UV} / \mathrm{H}_{2} \mathrm{O}_{2} / \mathrm{O}_{3}$, and Ultrasound [31-34]. These AOPs are based on the generation of unstable strong oxidants like hydroxyl free radicals $(\mathrm{HO} \cdot)$. The $\mathrm{HO}$ - is extremely reactive due to unpaired electron and it can destroy a broad range of non-biodegradable organic compounds that are unaltered by conventional methods. The possibilities of chemical pathways for $\mathrm{HO}$ - production in different AOPs are given in Table 3.

Cold plasmas are non-equilibrium non-thermal plasmas due to the difference in the temperature between electrons ( $\mathrm{Te}$ ) and other plasma species and the fact that in active plasma volume overall gas temperature $(\mathrm{Tg})$ is close to ambient [35-40]. In these plasmas, 


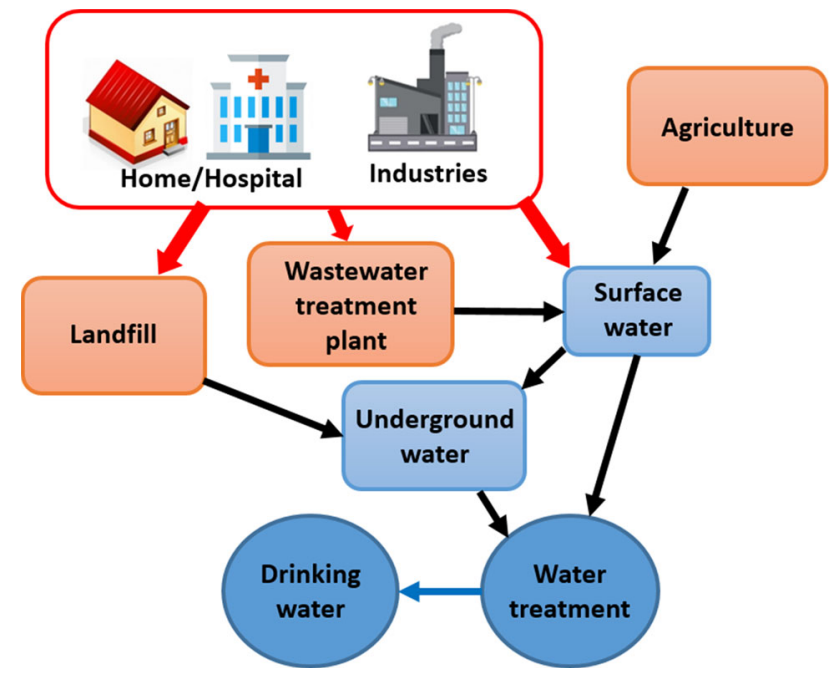

Fig. 1 Source of OMPs and their flow in the environment

highly energetic electrons play a key role in triggering chemical reactions and governing plasma chemistry via processes of excitation, ionization, dissociation, etc. $[36,38,41-44]$. On the other hand, in the thermal plasma system, Te and $\mathrm{Tg}$ are similar so these systems can be considered to be in local thermodynamic equilibrium. Comparison of both types of plasma-based on electron temperature, electron density and gas temperature is presented in Table 4 . The range of plasma properties depends on the type of plasma source, discharge, power signal, working gas, and much more. In terms of energy consumption, the cold plasma system requires lower energy to generate reactive species than thermal plasma system $[38,45-48]$.
Table 1 List of some commonly observed OMPs in water bodies

\begin{tabular}{lll}
\hline Class of OMPs & Sub-categories & Ref. \\
\hline Dyes & Azo & {$[11]$} \\
& Anthraquinone & {$[12]$} \\
& Sulfur & {$[13]$} \\
& Nitro & {$[14]$} \\
& Triarylmethane & {$[14]$} \\
Pharmaceuticals & Antibiotics & {$[15]$} \\
& Hormones & {$[16]$} \\
& Anticonvulsants & {$[17]$} \\
& NSAIDs & {$[18]$} \\
& Antihypertensives & {$[19]$} \\
& Antidepressants & {$[20]$} \\
Pesticides & Herbicides & {$[21]$} \\
& Fungicides & {$[22]$} \\
& Insecticides & {$[23]$} \\
& Rodenticides & {$[24]$} \\
& Bactericides & {$[25]$} \\
\hline
\end{tabular}

For decades non-equilibrium plasmas operating at low pressures have been used in various applications due to their rich chemistry $[35,37,50-53]$. Thus, cold atmospheric plasmas technologies have been considered a viable alternative to low-pressure plasma mainly due to the numerous applications that include samples that cannot undergo a vacuum $[36,38,54-65]$. However, ignition and sustaining of cold atmospheric pressure plasmas are more challenging due to the considerably higher breakdown voltage and set of parameters usually falling in the unfavorable region of Paschen's curve $[43,63,66-$ 68]. These issues have been overcome by using noble gasses as feeding gas, electrode geometry, operation frequency, type of power supply, etc. The cold atmospheric

Table 2 Characteristics of some examples of industrial wastewaters

\begin{tabular}{llllll}
\hline Physico-chemical parameters & & & & \\
\cline { 2 - 5 } & COD & BOD & pH & TSS & References \\
\hline Textile & $3300-3500$ & $2100-2300$ & $8.2-9.6$ & $350-410$ & {$[26]$} \\
Pharmaceuticals & $4000-6000$ & $300-1500$ & $6.5-8.0$ & $600-700$ & {$[27]$} \\
Pesticides & $6000-7000$ & $2000-3000$ & $12-14$ & $250-300$ & {$[28]$} \\
\hline
\end{tabular}

All values are in mg/L except $\mathrm{pH}$, COD - Chemical oxygen demand, BOD - Chemical oxygen demand, TSS - Total suspended solids

Table 3 HO generation mechanism by various AOPs

\begin{tabular}{ll}
\hline Processes & Reactions \\
\hline $\mathrm{H}_{2} \mathrm{O}_{2}-$ Fenton & $\mathrm{H}_{2} \mathrm{O}_{2}+\mathrm{Fe}^{2+} \rightarrow \mathrm{Fe}^{3+}+\mathrm{HO}+\mathrm{OH}^{-}$ \\
$\mathrm{UV} / \mathrm{TiO} 2$ & $\mathrm{TiO}_{2}+\mathrm{h} \nu \rightarrow \mathrm{e}^{-}+\mathrm{h}^{+} \mathrm{h}^{+}+\mathrm{H}_{2} \mathrm{O} \rightarrow \mathrm{H}^{+}+\mathrm{HO}$. \\
$\mathrm{O}_{3} / \mathrm{H}_{2} \mathrm{O}_{2}$ & $2 \mathrm{O}_{3}+\mathrm{H}_{2} \mathrm{O}_{2} \rightarrow 2 \mathrm{HO}+3 \mathrm{O}_{2}$ \\
$\mathrm{UV} / \mathrm{H}_{2} \mathrm{O}_{2}$ & $\mathrm{H}_{2} \mathrm{O}_{2}+\mathrm{UV} \rightarrow 2 \mathrm{HO} \cdot$ \\
$\mathrm{UV} / \mathrm{H}_{2} \mathrm{O}_{2} / \mathrm{O}_{3}$ & $2 \mathrm{O}_{3}+\mathrm{UV}+\mathrm{H}_{2} \mathrm{O}_{2} \rightarrow 2 \mathrm{HO}+3 \mathrm{O}_{2}$ \\
$\mathrm{Ultrasound} / \mathrm{UV} / \mathrm{O}_{3}$ & $\mathrm{Ultrasound}+\mathrm{UV}+\mathrm{O}_{3} \rightarrow \mathrm{HO}$. \\
\hline
\end{tabular}


Table 4 Characteristics of non-thermal plasma and thermal plasma

\begin{tabular}{llll}
\hline & Non-thermal plasmas & Thermal plasmas & Reference \\
\hline Plasma state & $\mathrm{Te}>>\mathrm{Tg}$ & $\mathrm{Te} \approx \mathrm{Tg}$ & {$[41,49]$} \\
Electron temperature & $1-10 \mathrm{eV}$ & $\sim 1 \mathrm{eV}$ & \\
Electron density & Lower electron density $\left(<10^{19} \mathrm{~m}^{-3}\right)$ & High electron density $\left(<10^{21}-10^{26} \mathrm{~m}^{-3}\right)$ & \\
Gas temperature & $300-1000 \mathrm{~K}$ & $10000 \mathrm{~K}$ & Arc plasma \\
Discharge type & Corona, Glow, Streamer & & \\
\hline
\end{tabular}

Te-electron temperature, $\mathrm{Tg}$ - gas temperature

$1 \mathrm{eV} \approx 10000 \mathrm{~K}$

pressure plasmas are fulfilling the major requirements, which is the production of highly reactive species at low gas temperature and this characteristic of cold atmospheric pressure plasmas is the main reason for their beneficial effect in wastewater treatment sectors [69$72]$.

Apart from other approaches for the realization of AOPs, nowadays, cold plasma-based oxidation techniques have gained a lot of interest. It is shown that this type of plasma can be used to degrade a variety of toxic OMPs in water such as pharmaceuticals, organic dyes, pesticides [30,73-76]. Cold plasma is responsible for the formation of many reactive oxygen species (e.g. $\mathrm{HO} \cdot, \mathrm{O} \cdot, \mathrm{HO}_{2} \cdot, \mathrm{O}_{3}, \mathrm{H}_{2} \mathrm{O}_{2}$, etc.), as well as ultraviolet light (UV), electric field, and sometimes shockwaves $[10,42,58,77-80]$. Plasma generated reactive species have high oxidation potential and they can react and eliminate many stable OMPs at low temperature, at atmospheric pressure, and without using any kind of hazardous chemicals. For example, plasma generated oxidants $\mathrm{HO} \cdot, \mathrm{O} \cdot \mathrm{O}_{3}$, and $\mathrm{H}_{2} \mathrm{O}_{2}$ have oxidation potentials of $2.86 \mathrm{~V}, 2.42 \mathrm{~V}, 2.07 \mathrm{~V}$ and $1.78 \mathrm{~V}$, respectively. These oxidation potentials are all higher than chlorine $(1.36 \mathrm{~V})$ [77,81], which is sometimes used as a bleaching agent to reduce colour in industrial effluents [82]. Moreover, the treatment of polluted water by using chlorine is not an eco-friendly process $[83,84]$. The cold plasma grants abundant formation of highly reactive species without adding chemical agents. Plasma treatments will not add to a secondary pollution and during the processing creates less toxic transformation intermediates that are biodegradable $[85,86]$. We can consider plasma decontamination processes as an ecofriendly technology. But one needs to be aware that some of the species may persist in the treated water and might be harmful to some aquatic life [87-89]. Moreover, the cold plasma system can be used alone or in a combination of conventional wastewater treatment techniques $[72,90]$.

In the last decade, many authors have studied the use of cold plasmas in applications for wastewater treatment. A few reviews have been carried out where authors discussed previously obtained results based on the treatment of various compounds dissolved in water (e.g. dyes, phenol, pharmaceuticals, surfactants, pesticides, personal care products, etc.) by plasma technology. In the review of Magureanu et al. [10], the overview of published data between 1996 and 2013 on the treat- ment of various pharmaceuticals by plasma is discussed. In this publication, they assess various reactor configurations and experimental parameters and related their influence to the performance of the plasma system. It was observed that the plasma generation in the gaseous phase over thin water film by DBD or corona was frequently performed for the removal of pharmaceuticals. In 2014, Hijosa-Valsero et al. [30] reviewed different plasma reactors and their operating conditions used for the degradation of various organic compounds, such as volatile organic carbon, phenols, dyes, pharmaceuticals, personal care products, and surfactants. According to their review, they stated that generation of plasma at the gas-liquid interface was more efficient for degradation as well as for the energy yield than the case when plasma was generated in the liquid phase. In 2010, the removal of various classes of dyes by utilizing plasma is reviewed by Malik, [71]. In his review, the various plasma reactors were discussed and compared including the energy efficiency. It was found that the formation of pulsed corona discharge in fine droplets and over thin water film was the most effective approach among those analyzed. In 2006 and 2014, Jiang et al. [69] and Locke, [91] reviewed the use of cold plasma reactors with varied of reactor configurations for the degradation of phenol and phenolic compounds. They showed that cold plasma can effectively degrade range of phenolic compounds. Another investigation on the combined effect of heterogeneous catalysts and cold plasmas for the removal and mineralization of organic pollutants from water is summarized in the critical review of Russo et al. [92]. They concluded that catalysts played a significant role to enhance the performance of the plasma systems. A recent review by Barjasteh et al. [93] illustrated the overview of cold plasma for water treatment with a focus on the inactivation of bacteria and degradation of some of the organic compounds.

In recent years, a continuation of work on the treatment of dyes, pharmaceuticals and pesticides by plasma has been presented in many publications. However, it was noticed that there were limited review studies performed on papers published in the last 5 to 6 years. In this article, we tried to make an up-to-date review of recent investigations that have not obtained attention, as well as on research papers that were published in the last almost 10 years. All gathered data in this review can be used for easier selection of the most suitable plasma source for degradation of three different 
types of OMPs (pesticides, pharmaceuticals and dyes). We have tried to discuss the implementation of plasma sources with various operational parameters and their effects on the degradation efficiency of OMPs. Where possible we have tried to take into account the energy efficiency of the above mentioned plasma sources.

This article presents a literature review on the degradation of various OMPs such as pharmaceuticals, organic dyes, and pesticides in wastewater under the cold atmospheric plasma treatments with a special focus on plasma sources, reactor configuration as well as some operating parameters that influence the degradation of specific OMPs. After general information about different kinds of plasma sources employed for OMP treatment, the paper describes specific approaches used for the degradation of organic dyes, pharmaceuticals and pesticides. For each pollutant type, we performed an excessive literature survey to obtain published information on various sources in terms of design, working conditions and plasma properties as well as treatment parameters and removal efficiency. We put through a comparison of different sources based on specific plasma and sample parameters and make conclusions for each pollutant type regarding plasma application.

\section{Removal of organic micropollutants by using cold atmospheric plasmas}

For several years, cold plasma discharges have been extensively used for the elimination of organic pollutants from water [72,94-97]. Many different plasma sources, e.g. corona, dielectric barrier discharge (DBD), atmospheric pressure plasma jet (APPJ), gliding arcs, and others have been investigated for wastewater treatment. They operate with various power supply signals (continuous wave at the wide range of frequencies $-\mathrm{Hz}$ to $\mathrm{kHz}$, pulsed voltage signals, etc.), electrode geometries such as a needle to plate, pin to ring, pin to pin and many other, as well as a variety of working gases and their mixtures (e.g. air, oxygen, argon, etc.) and have been extensively tested for the removal of different OMPs.

Generally, cold atmospheric plasma setups used for liquid treatments can be divided into three categories: discharge above the liquid surface, discharge in bubbles, and direct discharge inside the liquid, and have been investigated by many researchers to study plasmaliquid interface phenomenon. Schematics of typical arrangements are shown in Fig. 2 but in all three categories, there are many electrode geometries used to produce plasma in particular experiments $[42,79]$.

The setups where plasma is formed above the liquid surface and in bubbles are commonly used for wastewater treatment whereas direct discharge inside the liquid is not frequently employed. In the case of a discharge above the liquid surface, plasma species are formed in the gas phase near the liquid surface and then transferred inside the liquid sample where they trigger degra- dation of OMPs in water $[45,76]$. In the case of bubbles in the liquid, plasma is again formed in the gaseous phase inside the bubble and reactive species originate from separate plasma sites and enter the sample. So, in general, the mechanism behind these two approaches is very similar. The formation of plasma species above liquid has been studied and it is strongly dependent on the plasma source, electrode geometries, working gas, reduced electric field $[38,72,98]$. The next phase in plasma treatment, the interaction of plasma with liquid is an overly complex phenomenon with many processes occurring simultaneously: ionization, excitation and dissociation in the gaseous phase, heterogeneous mass transfer, chemical reactions in bulk liquid, evaporation, electrolysis, and so on $[42,98,99]$.

When the cold plasma is introduced over a liquid surface in presence of surrounding air, the interaction environment can be divided into three parts - plasma in the gas-phase, plasma-liquid interface, and the bulk liquid phase, as schematically shown in Fig. 3 [98]. Reactive species generated in the gas phase can diffuse into the liquid or trigger chemical reactions within the liquid in order to produced secondary species. These reactive oxygen and nitrogen species were formed in the gaseous, interface, and liquid phase either in plasma with an addition of a noble gas (e.g. argon) or only in the plasma formed in surrounding air over the liquid surface $[63,98]$. In the case of discharge above the liquid surface, the degradation rate of OMPs inside water depends on the formation of reactive species near the interface as well diffusion/penetration of reactive species from gas to the bulk phase $[76,100]$.

Apart from this approach, plasma can be ignited inside the liquid with or without using an external gas source. The generation of plasma inside liquid water with the bubbling of gases for the removal of OMPs has been investigated by many researchers $[73,101,102]$. Formation of the discharge in bubbles could improve the interfacial areas between plasma generated reactive species and OMPs and consequently increase the elimination rate of pollutants. Additionally, mass transfer from the gaseous environment to the bulk phase can also enhance through external gas bubbling. The most frequently used plasma sources for the generation of discharge inside bubbles are different corona geometries and DBD $[45,73,103,104]$, whereas, for initiation of a discharge directly inside liquid without the introduction of feed gases, electrode configuration creating corona discharge has been employed [105].

\subsection{Removal of organic dyes}

One large group of organic micropollutants are dyes that are commercially used in textile industries. Statistically, around $20 \%$ of industrial water pollution is caused by the discharging of dye effluents [106]. It is one of the biggest contributors to the water pollution. Consequently, some dyes are responsible for the catastrophic damage to aquatic ecological systems ascribed to their stability in nature $[107,108]$. Besides, recent 
studies have been illustrated that some dyes are carcinogenic $[107,109]$. Some of the dyes are difficult to decompose by conventional water treatment methods [110-112]. For almost 20 years wide research has been carried out on the degradation of organic dyes in solution by cold plasma $[77,94,113]$. In plasma-based degradation of organic dyes in solution, there are several plasma sources such as corona, DBD, gliding arc, APPJ that have been evaluated with different reactor configurations, continuous and pulsed voltage signals, input powers, working gases, etc. Generally speaking, cold plasma-based advanced oxidation methods show great potential in mineralization of organic dyes into $\mathrm{CO}_{2}$ and $\mathrm{H}_{2} \mathrm{O}$ or decomposition to the less hazardous intermediates [86,90].

Results of the different studies on the cold plasmabased degradation of organic dyes are given in Table 5 as a result of a survey of the literature published in the last 18 years. For selected target compounds we listed characteristics of plasma sources and operating parameters used for the decontamination as well as parameters related to the treatment, as they were stated in the reference. In cases where one publication contained several pollutants treated under the same conditions, we grouped the results.
Corona discharge with various reactor configurations has been introduced by many researchers for the treatment of organic dyes. In the case of corona discharge, mostly the plasmas were formed in the gas phase over the solution and inside bubbles. Magureanu et al. [74] evaluated the elimination of methylene blue from aqueous solution by using a pulsed high voltage corona discharge with multi-hollow needle electrodes (6 array of needles). The needle electrodes were situated at the bottom of the reactor and a grounded electrode was placed about $5 \mathrm{~cm}$ above the tip of the needles. Both electrodes were located inside the liquid and discharge takes place in bubbles inside dye solution. The paper presented results obtained when different feed gases (air, argon, and oxygen) were bubbled in the solution through the needles. The multi-needle electrodes promote a large volume of plasma which leads to enhance the interaction between reactive species and dye solution. It was observed that at the same external power input degradation of methylene blue was enhanced in the particular order of feed gases: air < argon < oxygen. They have explained that more efficient degradation in oxygen and argon in comparison to air plasmas was due to fact that energy delivered to plasma in these gases is used to generate more reactive species, whereas, in air, some

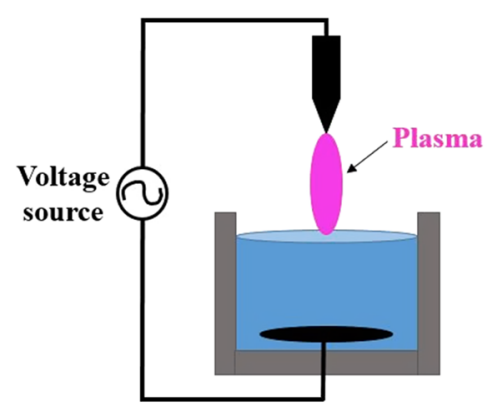

(a) Discharge above liquid surface

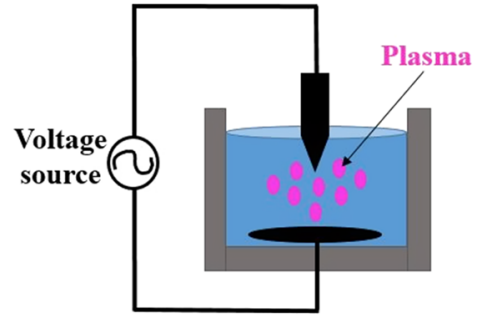

(b) Discharge in bubbles

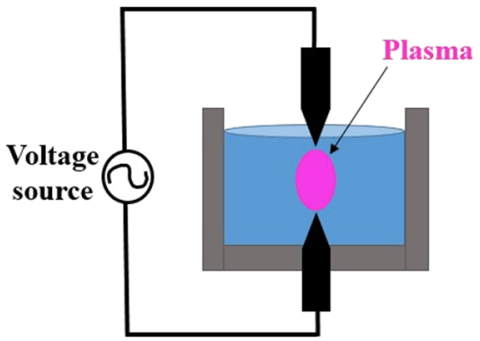

(c) Discharge in liquid

Fig. 2 Schematics of experimental setups used in studies of liquid treatments with cold plasma

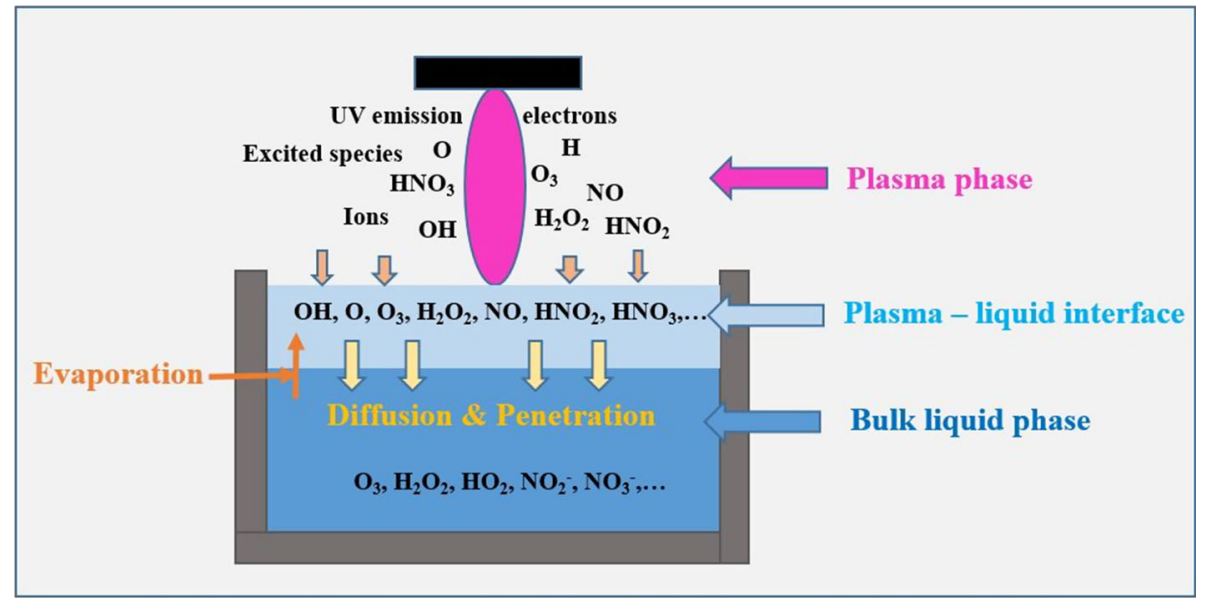

Fig. 3 Schematic representation of plasma-generated short and long-lived species in the gas phase, at the plasma-liquid interface, and bulk liquid 


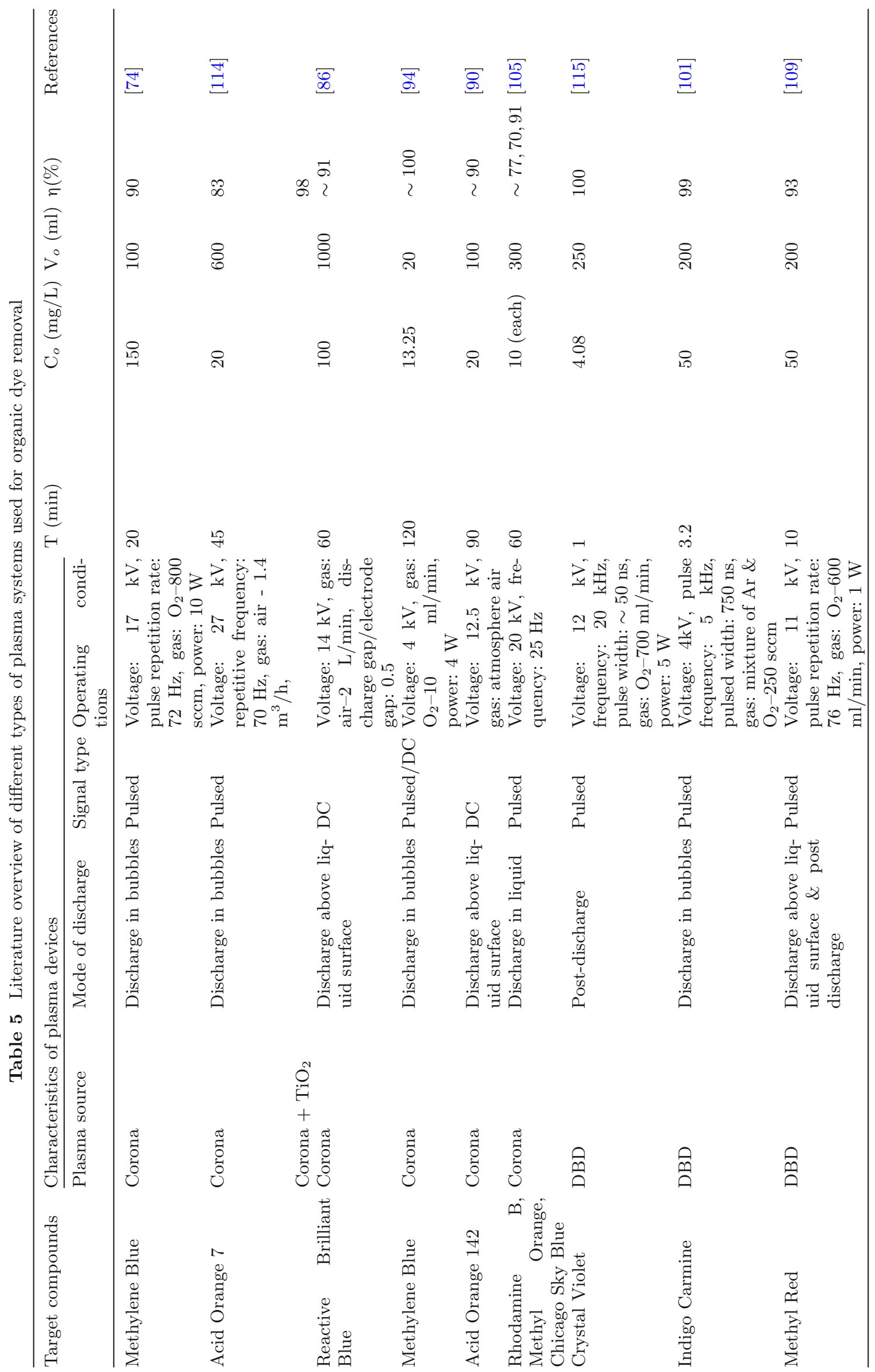




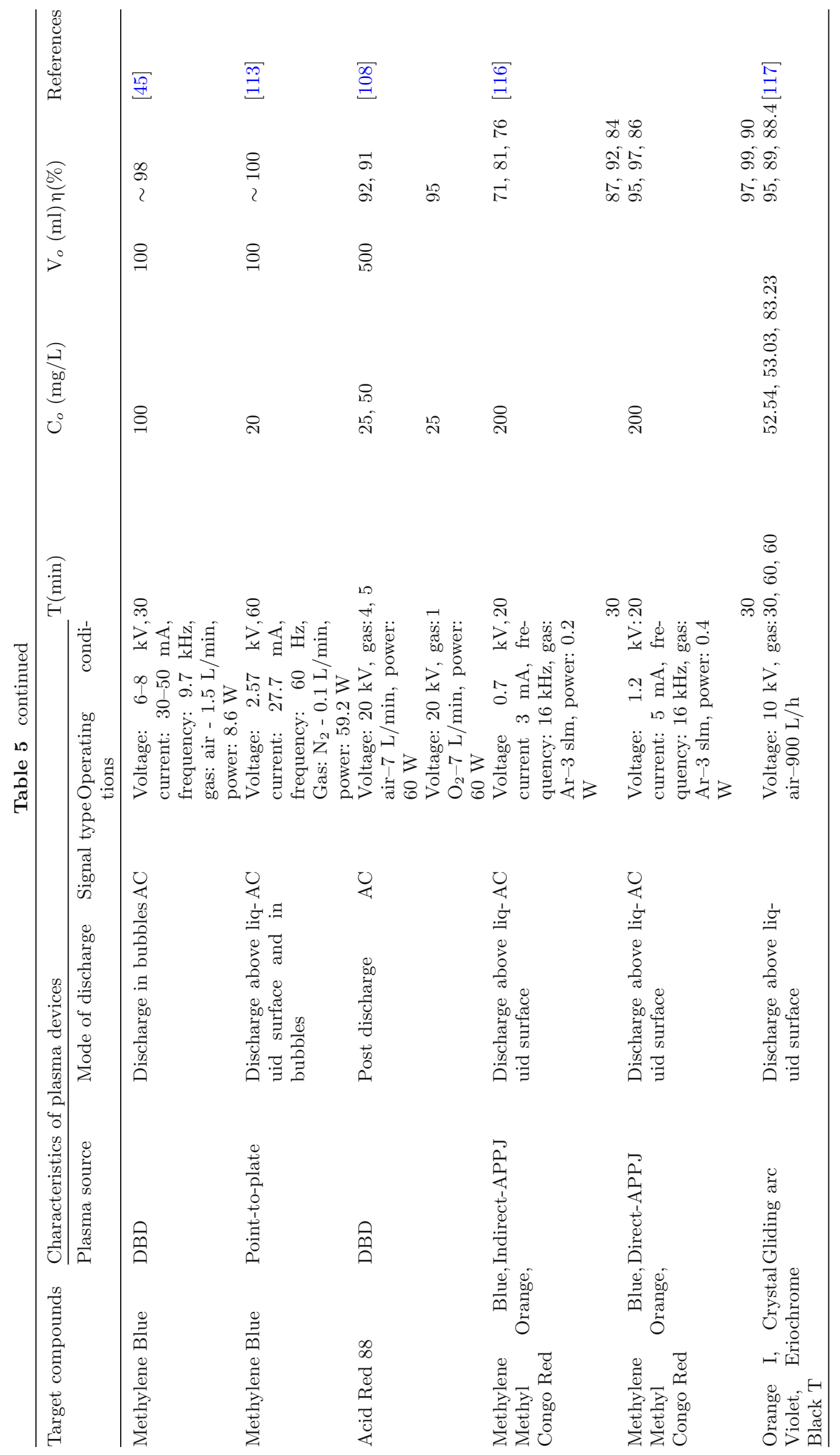




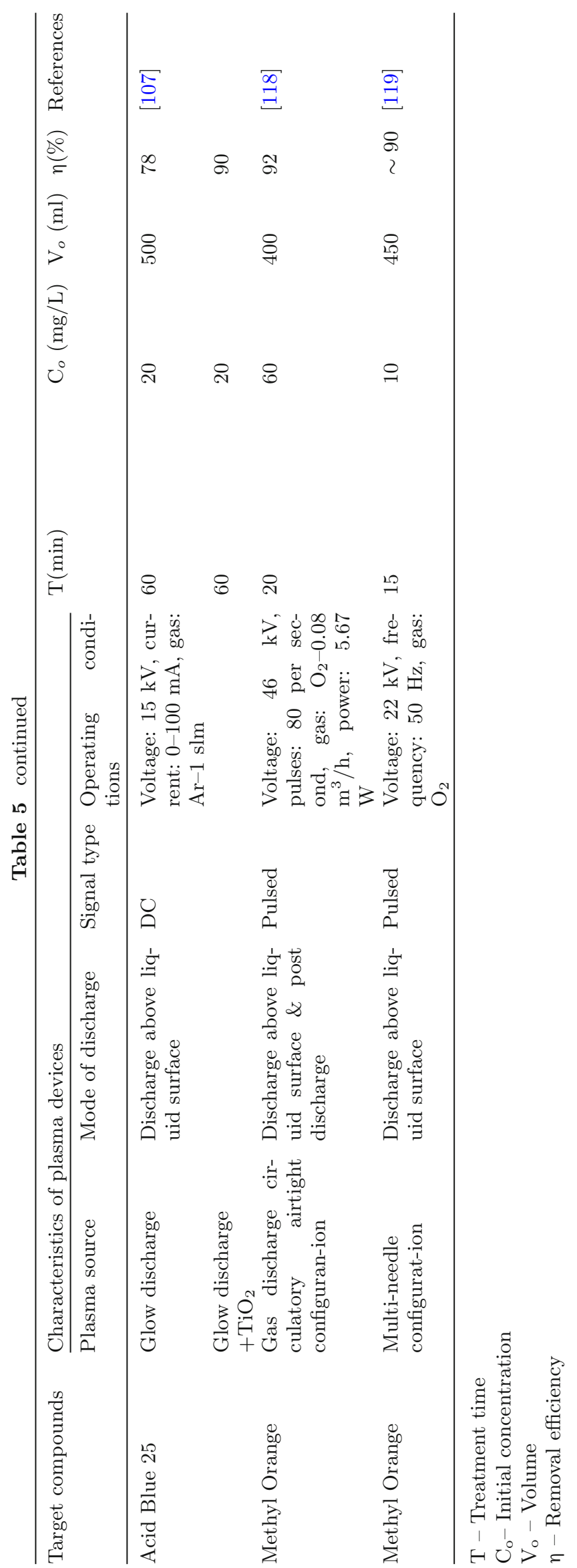


part of the energy is consumed for the dissociation of nitrogen molecules. On the other hand, they reported that the degradation of methylene blue depended on initial dye concentration and volume of the solution, i.e. higher dye concentration degraded more rapidly in smaller volumes. Li et al. [114] investigated the degradation of Acid Orange 7 dye in a pulsed discharge reactor with a needle-to-plate electrode configuration and with air bubbling into the reaction system in the presence of $\mathrm{TiO}_{2}$. They observed more decoloration efficiency of dye by adding $\mathrm{TiO}_{2}$ particles into the reactor, which attributed to photocatalysis in the presence of the ultraviolet light produced in the pulsed plasma system. They also found that the decoloration efficiency of dye was improved by increasing the input power. Jingyu et al. [86] studied reactive brilliant blue dye removal with a point-to-plane DC corona discharge reactor using air as a working gas while the discharge was ignited over the liquid surface. In this case, 72 stainless-steel pin electrodes were powered and stainless-steel plate immersed in dye solution served as a grounded electrode. The idea behind the multi-pin electrodes is to enable the large plasma volume on the liquid surface by physically increasing the number of reaction points. The authors evaluated the effect of the ratio of the discharge gap and the adjacent point distance between two electrodes on decoloration efficiency. The main degradation byproducts that were traced were 2,5-diritrobenzoic acid, 1,2-diacetylenzene, and 3- nitrobenzonic acid.

Malik et al. [94] have designed a pulsed corona discharge reactor with needle-plate type electrodes for the decolorization of methylene blue and they studied the influence of oxygen and ozone bubbling on the dye decomposition. The removal efficiency was much higher when a combination of oxygen and ozone was bubbled in compared to plasma in pure oxygen and without bubbling of any gases. The presence of additional oxygen and ozone enhances the production of chemically reactive species in water, which leads to a higher degradation of the dye. They also suggested that the removal efficiency of dye was higher in distilled water than in tap water, probably due to the interaction of plasma generated species with impurities in tap water. Recently, Fahmy et al. [90] used a DC corona discharge to eliminate Acid Orange 142 from the water where the plasma was generated in atmospheric air at the surface of the sample in a small discharge gap. It was found that the degradation rate was increased by either increasing the applied voltage or decreasing the discharge gap. Higher applied voltage influenced generation of more energetic electrons and metastables due to the stronger electric field, which led to the formation of more reactive oxygen species. In the study of Sugiarto et al. [105], pulsed streamer corona discharge with a ring-to-cylinder electrode geometry system was used to remove dyes including rhodamine $\mathrm{B}$, methyl orange, and Chicago sky blue from water and plasma was ignited inside the solution. The sample was recirculated inside the plasma reactor. At the given power input, the degradation rate of dyes depended on the initial $\mathrm{pH}$ of the solution and the best degradation observed in the acidic medium was caused by faster reactivity of hydroxyl radicals with dye molecules at lower $\mathrm{pH}$. Degradation of dyes was higher with the addition of hydrogen peroxide into the solution, as a consequence of the dissociation of hydrogen peroxide by ultraviolet light from the plasma. Additionally, they concluded that the pulsed streamer corona discharge reactor with two rings was more efficient than one ring because it provided larger contact area between the plasma streamer and the solution.

DBD has also been used extensively for the degradation of various types of organic dyes. DBD plasma formed between two electrodes, however, at least one electrode covered with a dielectric material, such as glass, quartz and so on. For most of the cases, the postdischarge and discharge in bubbles type of configurations have been widely reported in the papers for the removal of organic dyes. Rahimpour et al. [115] performed an investigation on the removal of crystal violet dye from a liquid via a post-discharge pulsed DBD reactor, using oxygen as a working gas. In the analysis, oxygen was supplied into the DBD reactor and the effluent gas was bubbled through the solution to enhance the mass transfer of reactive oxygen species into the solution which in turn resulted in higher degradation of the dye. The addition of argon in the working gas at the fixed input power, lead to a higher degradation of dye in comparison to pure oxygen case. This effect is due to the formation of more ozone molecules caused by higher dissociation of oxygen molecules in the presence of argon metastables and energetic electrons in the plasma system. The degradation kinetics of crystal violet was found to follow the first-order reaction. A complete elimination of total organic carbon (TOC) was obtained after the plasma treatment, which revealed the full mineralization of treated solution from unwanted organic carbon. In the study of Muradia [101], a parallel plate DBD plasma system was used for the decolorization of indigo carmine. The powered (upper) electrode was a metal plate with punched holes and covered with mica sheets with porous grounded electrode made of graphite. The system was inside the solution and the working gas ( $\mathrm{Ar}, \mathrm{N}_{2}, \mathrm{He}$ ) was bubbled through the grounded electrode. It has been found that, at the fixed source voltage, the addition of oxygen in the mixture greatly improved the decolorization rate of dye in comparison to the pure argon case.

The degradation of methyl red in an aqueous solution was performed with a pulsed DBD in the coaxial configuration by Piroi et al. [109] where oxygen was used as working gas. They proposed such a configuration to enhance the contact between plasma generated species and the dye, while the solution was recirculated from the reservoir to the DBD reactor in the form of a thin layer of water flowing on the surface of the inner electrode of the reactor. Additionally, the effluents from the DBD reactor were bubbled through a reservoir containing the solution, promoting the interaction between ozone and dye molecules and faster degradation of dye. Since oxygen was used as working gas, ozone was generated due to oxygen discharge in the $\mathrm{DBD}$ reactor, and it was the main oxidizer in the 
effluent gas. In this paper author also observed that degradation kinetics followed the first-order and that faster degradation of the dye occurred with lower initial dye concentration. Besides, they also found several by-products after the treatment, some of them are identified: 2-ethoxy-2 methylpropane, 2-tert-butoxyethanol, 3-metoxy-3methyl-1-buthanol. Recently, an air DBD reactor with a glass bead packed bed and microporous diffuser plate was developed by $\mathrm{Wu}$ et al. [45] for the treatment of wastewater containing methylene blue. The plasma was formed in the glass bead packed bed and the species were transferred into the dye solution via a microporous diffuser plate. The role of the microporous diffuser plate inside the DBD reactor was to enhance the mixing between propagating plasma species and the solution. Additionally, plasma species were generated in micropores on the diffuser plate and they interacted with dye molecules. The authors suggested that the packing beads in the plasma zone played a significant role to produce more reactive species in the reactor as they enable the formation of strong electric fields in the cavities. The degradation was higher for the lower initial concentration of dye. On the other hand, it was found that the influence of initial pH and conductivity of the solution on the dye degradation was small. They proposed a possible degradation mechanism involving energetic electrons, ozone, and hydroxyl radicals responsible for the formation of intermediate compounds and their subsequent elimination after the treatment.

Benetoli et al. [113] evaluated the removal of methylene blue from water by using a point-to-plate type plasma reactor configuration. Corona discharge was generated in nitrogen over the liquid surface. Nitrogen was bubbled in the solution from the bottom of the reactor. The initial temperature of the solution was particularly important for the removal, and it has been found that the removal efficiency improved when the temperature was increased. Several long-lived nitrogenbased species were traced inside the solution and they found zeroth-order degradation kinetics of methylene blue for higher initial concentration, whereas first-order for the lower initial concentration. In the study of Tang et al. [108], a post-discharge of a DBD reactor was used for the removal of Acid Red 88 from aqueous solutions, with air containing $100 \%$ relative humidity and oxygen were supplied as the working gas. The gas effluents containing reactive species from the DBD plasma were injected through the bottom of the solution reservoir through an annular porous diffuser device. The degradation of Acid Red 88 was faster when pure oxygen was introduced into the DBD reactor than in the case of a mixture with air with $100 \%$ relative humidity, which implied that higher ozone generation was obtained with pure oxygen. The degradation process was fitted with the pseudo-first-order kinetics model and depended on the input power, initial dye concentration, gas flow rate, and initial $\mathrm{pH}$ value of the solution.

Apart from corona and DBD systems, a few studies have also been carried by authors for the treatment of organic dyes by sources such as APPJ, gliding arc, glow discharge. With these kinds of sources, generally, plasma occurred in the gas phase over the liquid surface. Attri et al. [116] compared two needle-type atmospheric pressure plasma jets (called indirect and direct APPJ) for the degradation of congo red, methyl orange, and methylene blue dyes and argon was used as a plasma gas for both reactors. The indirect APPJ was made with a hollow inner needle electrode and the grounded ring-type electrode (copper tape) that was placed outside the glass tube surface, whereas in the case of direct APPJ, the copper tape as a grounded electrode was positioned on the outer side of the bottom of the vessel. The degradation of all three dyes was higher when direct APPJ was introduced to the sample in comparison to the indirect jet. However, the sample volumes were not reported. According to the optical characterization of both sources, they identified higher intensity of excited argon species in direct APPJ, which contributed to the formation of a higher density of reactive species due to collisions between excited argon species and water molecules. The authors suggested that the hydroxyl radicals were the main oxidative species produced in plasma that was responsible for the degradation of dyes.

Decomposition of Orange I, Crystal Violet, and Eriochrome Black $\mathrm{T}$ dyes in the aqueous solutions under the action of gliding arc discharge was studied by Abdelmalek et al. [117]. The plasma was created between two diverging electrodes when humid air was supplied. It was found that the degradation of all three dyes followed first-order kinetics. On the other hand, they also reported that the mineralization of dyes decreased with a decrease in the plasma exposure time. Ghodbane et al. [107] evaluated a DC glow discharge reactor with a combination of photocatalyst $\left(\mathrm{TiO}_{2}\right)$ to remove Acid Blue 25 dye from the liquid medium. Argon was used as a feed gas and plasma was generated near the liquid surface in a closed reactor chamber with the absence of air. At the same treatment time, the presence of photocatalyst enhanced the destruction of Acid Blue 25. They reported faster degradation in strongly acidic conditions. Jiang et al. [118] designed a pulsed-discharge with the needles-to-plate electrodes operating in an airtight reactor system with plasma treated sample circulation They treated methyl orange as the target compound using oxygen as a working gas that was introduced from the bottom of the reactor into the discharge zone through the liquid sample. The needles, i.e. powered electrodes were located vertically above the dye solution while the grounded electrode was placed inside the solution. The plasma was generated between the needle electrodes and the liquid surface. The plasma-treated solution was injected into the reservoir containing the dye to enhance degradation. They obtained better degradation for lower initial concentrations and low volume of the compound. In the study of Sun et al. [119], multi-needle jet (with 24 needle electrodes) produced pulsed plasma that was used to treat aqueous solution containing methyl orange dye using different working gases (oxygen, air, argon, and nitrogen). A plate disc placed inside dye solution served as 
a grounded electrode and the plasma was formed in the gaseous phase, between needle electrodes and the dye solution. Decoloration rate was achieved in the following order of working gases, from higher to lower: oxygen $>$ air $>$ argon $>$ nitrogen. Moreover, it was reported that a smaller discharge gap was more effective in terms of degradation caused by the enhancement of the electric field in the gap, which leads to the formation of a large number of reactive species.

\subsection{Removal of pharmaceuticals}

The daily intensive consumption of pharmaceuticals has resulted in the increment of water pollution [97]. Many pharmaceuticals have been identified in the environment in both low and high concentrations [120]. It has been found that several pharmaceuticals released in the environment cause risk on both aquatic species as well as human health [97]. The greatest source of pharmaceuticals in the environment are effluents from wastewater treatment and drug manufacturing plants [121,122]. However, traditional wastewater treatment plants are not designed for the reduction of certain pharmaceuticals [123]. Therefore, cold plasma-based advanced oxidation processes have been investigated extensively to remove various non-biodegradable pharmaceutical compounds $[10,96,124]$.

Various cold plasma devices have been successfully applied by many researchers for the degradation of pharmaceuticals, as summarized in Table 6. We listed references based on different pharmaceutical contaminants or groups of contaminants together with plasma sources and treatment parameters used for their decomposition.

In the study of He et al. [73], a combination of corona discharge with a needle-type electrode and a $\mathrm{TiO}_{2}$ catalyst was demonstrated for decomposition of tetracycline antibiotic in an aqueous solution with plasma generated in the liquid when air was bubbled. The powered electrode was situated at the top of the reactor and the tip was immersed in the solution, whereas grounded electrode was attached within the solution. In this case, the plasma was driven by a high voltage AC power signal. It has been found that high input power and low initial concentration of antibiotics were beneficial for faster degradation, while $\mathrm{TiO}_{2}$ catalyst also played a significant role in the degradation. According to the proposed degradation mechanism of tetracycline, they observed that several processes such as hydroxylation, deamination, oxidation, and opening of the aromatic ring were responsible for degradation. To increase the contact surface between plasma reactive species and solution, a plasma reactor with wetted-wall and pulsed highvoltage source was investigated by Rong and Sun [125] for the degradation of sulfadiazine. On the other hand, the authors explained that at higher pH (strong alkaline solution) lower degradation was due to the scavenging effect since hydroxyl radicals reacted with carbonate ions. They also investigated addition of hydrogen and hydroxyl radical scavengers and showed that this played a significant role in degradation. Hydrogen radical scavengers improved the degradation rate and hydroxyl radical scavengers inhibited the degradation. Moreover, several intermediates are identified before the almost complete mineralization of sulfadiazine.

Dobrin et al. [126] assessed a pulsed corona discharge reactor with 15 copper wires as electrodes and used oxygen to produce plasma at the water surface to remove drug diclofenac. The formation of long-lived reactive species such as hydrogen peroxide measured in the water and ozone was determined in the gas phase, where the concentration of hydrogen peroxide in the solution and ozone in the gas phase was dependent on the plasma treatment time. Complete removal of diclofenac and several carboxylic acids by-products (e.g. formic, acetic, oxalic, malonic, maleic, and succinic) was reported. A different type of corona discharge reactors operating with benchtop batch and benchtop flow-through systems were evaluated by Krause et al. [127] for removing carbamazepine, clofibric acid, and iopromide from an aqueous solution. In the case of benchtop batch configuration, pulsed corona discharge occurred in the air on the liquid surface, whereas in the system with the sample flow corona discharge was generated also in argon-air mixture over a thin water film. In both cases, the grounded electrode coated with catalyst was submerged inside the solution. The concentration of all target compounds decreased with an increase of the plasma treatment time. Several types of submerged electrodes (e.g. boron-doped diamond, iridium oxide, titanium, and iron) serving as a catalyst have been tested. Faster degradation of carbamazepine in the presence of a boron-doped diamond electrode has been observed in comparison to other submerged electrodes.

In order to enhance contact of an effective plasma area with the liquid, Banaschik et al. [128] used a pulsed corona discharge reactor with a coaxial geometry to eliminate seven pharmaceutical compounds (carbamazepine, diatrizoate, diazepam, diclofenac, ibuprofen, 17a-ethinylestradiol, trimethoprim) from water. The corona discharge was directly generated in the liquid by a wire-type electrode inserted in the center of the tube. The sample was continuously recirculated with about $80 \%$ of the total sample volume processed in the plasma reactor at the time. The complete degradation of diclofenac and ethinylestradiol was noticed. They discussed that the solution $\mathrm{pH}$ and concentration of longlived nitrogen species inside the bulk liquid were not varying significantly because the liquid was not in the contact with any kind of air discharge. They suggested that the short-time high-voltage pulses with fast-rising time lead to the efficient transfer of energy to electrons, whereas longer voltage pulses are prone to thermal losses. They proposed degradation pathways for phenol and found that the hydroxyl radicals were responsible for the primary degradation of phenol. Singh et al. [129] employed a pulsed corona discharge with multiple needles to remove various pharmaceuticals such as diclofenac, carbamazepine, and ciprofloxacin from water. Similarly, the plasma was created in ambient air 


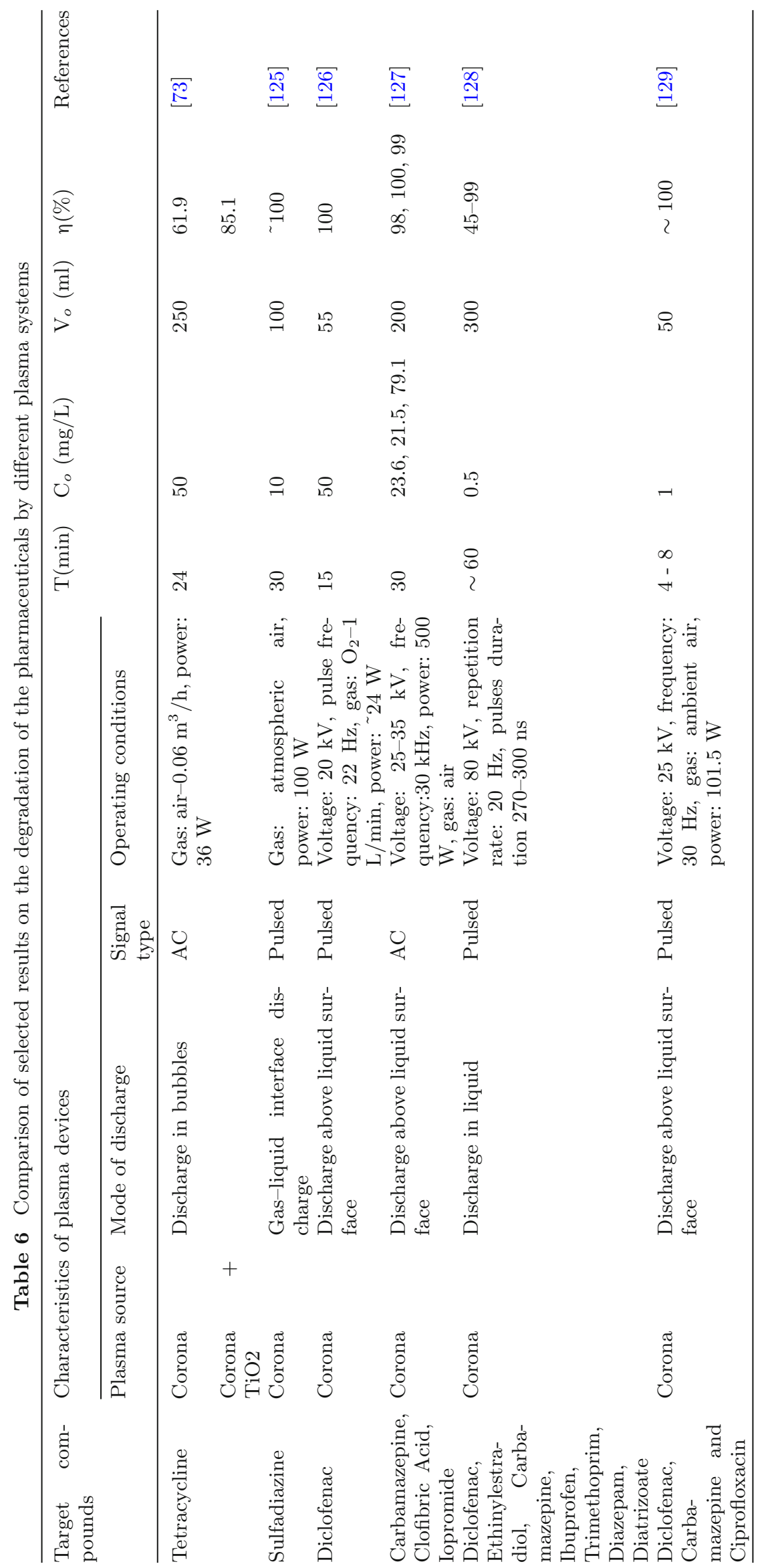




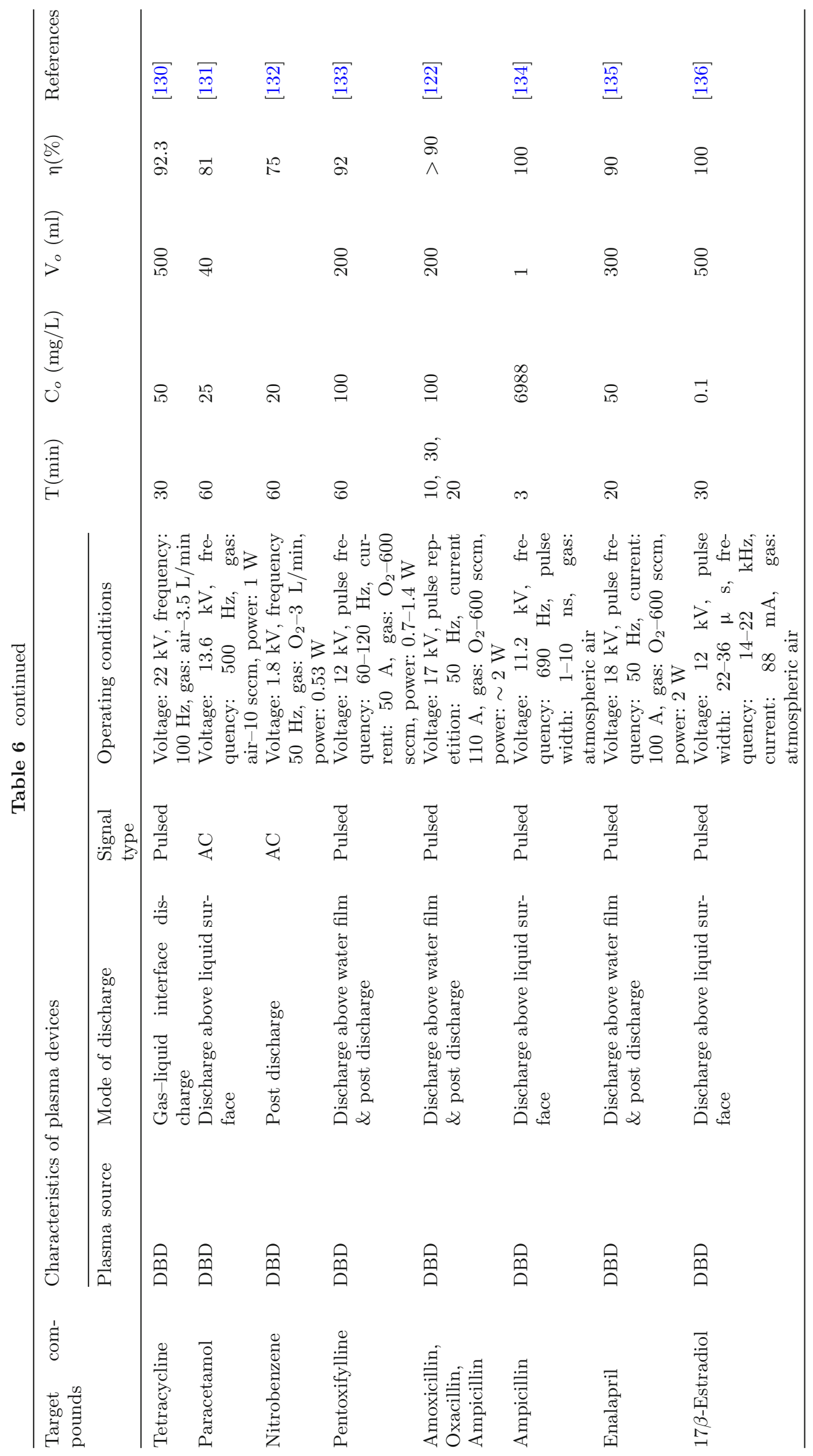




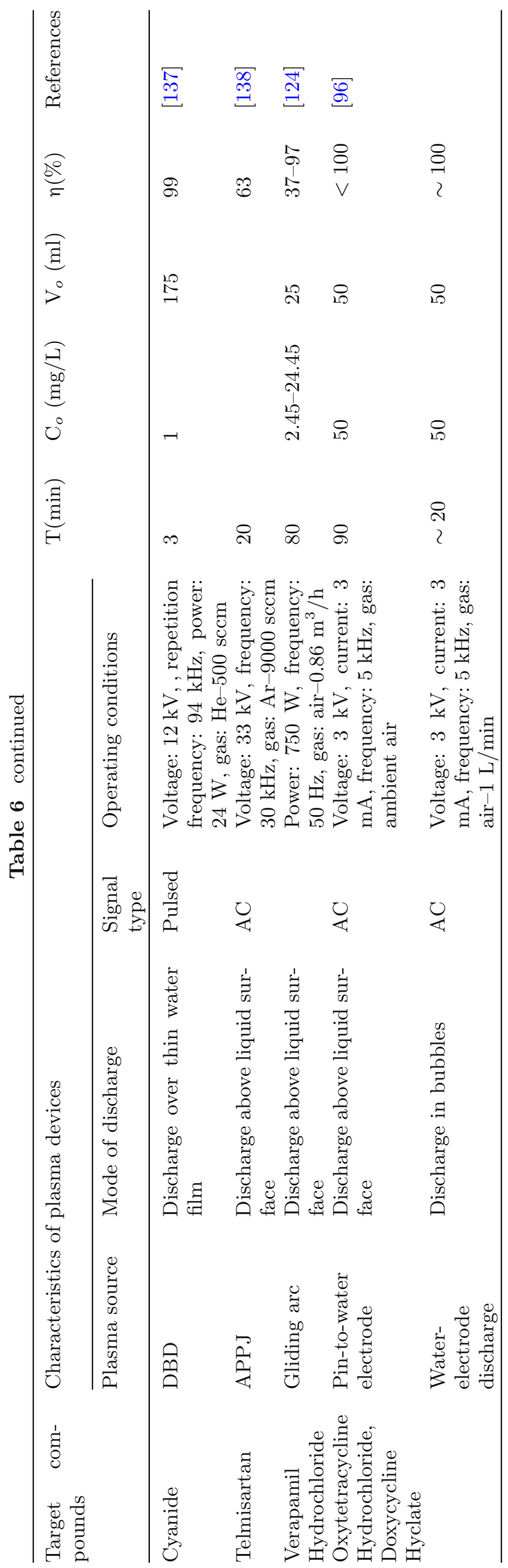


over the solution surface. They conducted a series of studies on the influence of various parameters like voltage, frequency, initial $\mathrm{pH}$, etc. on the degradation efficiency. They claimed that the degradation was faster in acidic conditions and revealed that more reactive oxygen species were formed for lower $\mathrm{pH}$ conditions. The degradation kinetics followed the first-order, and the oxidation rate decreased with an increase in initial concentration.

Recently, Hao et al. [130] used a pulsed coaxial DBD for the degradation of tetracycline in an aqueous solution. The screw-type electrode was connected to a high voltage signal and the aqueous solution was falling over it. The plasma was formed over water film while the air was introduced as a working gas. They reported that the screw-type electrode produced a strong local electric field at the tip, which resulted in a higher plasma intensity. They obtained a higher first-order oxidation rate constants with lower initial concentration of the pollutant compound and higher voltage of the pulsed signal, respectively. Additionally, several intermediates were identified. Baloul et al. [131] studied paracetamol removal by using a DBD plasma with a multiple needle-to-plate reactor configuration and different working gases (air, argon, and nitrogen) with plasmas generated between the tip of the electrodes and the liquid surface. The authors found that higher removal of paracetamol in air plasma. They noticed two types of discharge regimes, spark and streamer. It was observed that the formation of hydroxyl radicals in the spark regime was higher than in the streamer regime because the spark regime supported more evaporation and dissociation of water.

Nawaz et al. [132] investigated the degradation of nitrobenzene in water by utilizing a parallel-plate type DBD reactor with various working gases including oxygen, air, and nitrogen. In this configuration, the reactive species were formed in the DBD system and propagated into a reservoir containing nitrobenzene, so plasma effluent was reacting with the target molecules. They also tested the addition of hydrogen peroxide, $\mathrm{Fe}^{2+}$ ions and methanol in the solution. Hydrogen peroxide and $\mathrm{Fe}^{2+}$ ions played a significant role in enhancing degradation, whereas methanol greatly decreased the degradation rate due to its scavenging effect. The degradation process followed first-order kinetic models. In terms of application, nitrobenzene is used to make analgesic acetaminophen or paracetamol. Furthermore, Magureanu et al. [133] studied the decomposition of pentoxifylline by using a pulsed coaxial DBD reactor with oxygen used as the working gas. The sample solution was introduced over the surface of the inner electrode using several holes from the top of the DBD reactor whereas the discharge occurred in the gaseous phase above the thin water film. The solution and gas effluent containing ozone was transferred into a reservoir at the bottom of the plasma reactor, where the post-discharge reaction occurred. The degradation was observed at the plasma-liquid interface as well as in the solution reservoir by bubbling of the gas effluent. Higher pulse frequency and lower initial concentration of pentoxifylline were noticed to be advantageous for higher degradation. Several by-products were identified before the almost complete degradation was achieved. The same pulsed coaxial DBD plasma reactor with the same conditions was used by Magureanu et al. [122] to remove antibiotics amoxicillin, oxacillin, and ampicillin from an aqueous solution. The researchers observed that amoxicillin was decomposed for the shortest treatment time, whereas oxacillin and ampicillin required longer times. In another study, Magureanu et al. [135] investigated the degradation mechanism of the enalapril compound by using the same plasma reactor. They suggested that processes such as hydrolysis, oxidation, and intra-molecular dehydration were responsible for the breakdown of enalapril. Higher mineralization was obtained at a longer plasma treatment time.

In the study of Smith et al. [134], plasma was generated in ambient air over the liquid surface by using a nanosecond pulsed DBD source with a floating electrode for the treatment of high concentrations of antibiotic ampicillin. The degradation rate was higher with increase in plasma treatment time. According to the results of the characterization of treated solutions, they claimed the complete degradation of ampicillin was achieved. Gao et al. [136] assessed pulsed DBD with a slightly different electrode configuration, where the plasma was formed in ambient air in between the ceramic crucible wall (dielectric) and the surface of the solution, that was used for the treatment of $17 \mathrm{~b}-$ Estradiol. A high-voltage wire type electrode was submerged in a ceramic crucible containing water, while another electrode was placed in the aqueous solution of pollutant. The experimental results showed degradation was dependent on the initial amount of pollutants, applied peak voltage, $\mathrm{pH}$, and type of water samples. On the other hand, with different water samples, the level of degradation was observed in the following descending order: ultrapure water, tap water, landfill leachate. The authors hypothesized that the lowest degradation of 17b-Estradiol with landfill leachate could be due to higher conductivity and existing impurities (e.g. organic and inorganic). They reported that higher conductivity caused formation of a weaker electric field and less reactive species in the solution which consequently had a negative influence on degradation. Hijosa-Valsero et al. [137] compared two DBD plasma reactors - conventional batch and coaxial thin falling water film for the removal of cyanide from aqueous solution with helium as a working gas in both plasma reactors. In a conventional batch-type reactor, plasma was formed directly underneath the Petri dish containing solution, while, in the other reactor, plasma was generated over the thin falling water film. It was found that a thin falling water film reactor had better performance in comparison to a conventional batch type caused by the large surface of aqueous solution exposed to the plasma. The degradation of cyanide in both types of DBD reactors followed the first-order kinetics. In medicine, the compound cyanide can be found in anti-hypertensive, sodium nitroprusside. 
Recently, Vasu et al. [138] used an APPJ with rod and ring-type electrode configuration for the decomposition of telmisartan, where the plasma occurred in argon gas over the liquid surface. However, a complete comparison with the other results could not be accomplished since the initial concentration and sample volume were not reported. Authors observed solution $\mathrm{pH}$ decreased and conductivity enhanced with an increase in treatment time and applied voltage. The degradation of telmisartan was observed as pseudofirst-order kinetics with applied voltage. Krishna et al. [124] evaluated the removal of Verapamil hydrochloride from water under the action of gliding arc plasma in air where the discharge was created between two divergent electrodes above the solution. The first-order degradation was obtained and a higher removal rate constant was noticed when the initial concentration of the target compound was lower. These researchers proposed a degradation mechanism with high energy electrons, ozone, and hydroxyl radicals playing dominant roles in the degradation. In a recent article, El Shaer et al. [96] compared two plasma reactors with different configurations - single pin-to-water electrode with plasma above air-water interface and a configuration with water as an electrode with plasma below the interface. The degradation of two antibiotics in water: oxytetracycline hydrochloride and doxycycline hyclate was examined. In the pin-to-water electrode configuration, a wire-type powered electrode formed plasma in air over the liquid surface. In the case of water-electrode configuration, the powered electrode was a hollow needle inserted in a glass tube that was located at the bottom of the vessel. The discharge occurred in the liquid phase when the air was bubbled through the needle. In both cases, grounded electrode was the copper plate placed along the vessel wall and submerged inside the liquid. They concluded that faster degradation was observed when the plasma generated inside the water sample than over the water surface.

\subsection{Removal of pesticides}

Pesticides are nowadays commonly used to protect crops, vegetables and fruits from pathogens [103]. Most of the pesticides discharged into water bodies come from the agricultural industries and through runoff from the agricultural soils [139]. A variety of pesticides (herbicides, insecticides, fungicides, etc.) have been observed in surface and ground waters. Even a low concentration (range of ng/L to $\mu \mathrm{g} / \mathrm{L}$ ) of pesticides in water can have negative effects on the environment and thus on public health $[102,140]$. Unfortunately, many pesticides are non-biodegradable while for certain pesticides conventional treatment methods are inefficient for degradation due to their chemical structure complexity [141]. Therefore, to eliminate the potential risks related to pesticides, it is necessary to treat wastewater containing pesticides before releasing them to the natural water recipient.
The oxidation of organic pesticides in water based on low-temperature plasma treatments has been employed by many authors in order to tackle this issue and it was found that plasma processing can successfully eliminate pesticides from water without formation of the secondary toxic by-products [142]. A number of research papers have been published on plasma sources for the degradation of pesticides in water and a comparison of selected data is presented in Table 7 .

Singh et al. [142] have designed a multiple needle-toplane pulsed corona discharge reactor for the treatment of an aqueous solution containing carbofuran, where the plasma was formed in ambient air (without any external feed gas) over the liquid surface. The tungsten needle high voltage electrodes were attached to the circular plate and located above the solution, whereas the ground electrode was fixed in the solution. The streamer propagation occurs due to the high intensity of local electric field over the tip of the needle electrodes. They studied the effect of several experimental parameters on the degradation of carbofuran, including applied pulsed voltage, pulsing frequency, initial carbofuran concentration, initial $\mathrm{pH}$ and dependence of the process on radical scavengers. It was observed that higher pulsing frequency and applied pulsed voltage favored faster degradation, suggesting that more reactive species were produced and transferred to the solution. On the other side, addition of radical scavengers $\left(\mathrm{HCO}^{3-}, \mathrm{CO}_{3}^{2-}\right.$ and humic acid) diminished the degradation by quenching the hydroxyl radicals. The degradation followed the first-order kinetics model, and the oxidation rate was higher for the lower initial concentration of carbofuran. Moreover, they identified seven intermediates compounds before complete mineralization. Bradu et al. [143] used a slightly different type of pulsed corona discharge reactor for the degradation of 2,4-dichlorophenoxyacetic acid herbicide in water, where oxygen plasma was formed in between a multiwire array (consisting of 20 copper electrodes) and the liquid surface. The solution was circulated from the reservoir to the plasma reactor while the plasma effluent that consisted mainly of oxygen and ozone was bubbled inside the solution from the bottom of the reservoir to induce post-discharge reactions. The concentration of ozone was measured in the plasma effluent and separately the same amount of ozone was introduced inside the reservoir using a solution for ozonation. They observed faster degradation when the plasma was generated at the gas-liquid interface and with the plasma effluent bubbled inside the solution in comparison to the ozonation alone. Additionally, when 2,4dichlorophenoxyacetic was treated directly by plasma without bubbling of effluent slower degradation was noticed than for both cases. In the study of Mededovic and Locke [144], a pulsed corona discharge with a combination of $\mathrm{FeSO}_{4} \bullet 7 \mathrm{H}_{2} \mathrm{O}$ electrolyte was employed for the degradation of atrazine in water The plasma was formed in between point-to-plane electrode inside the liquid. They claimed the addition of $\mathrm{FeSO}_{4} \bullet 7 \mathrm{H}_{2} \mathrm{O}$ leads to complete removal of the target compound caused by Fenton reaction between ferrous ions and plasma 


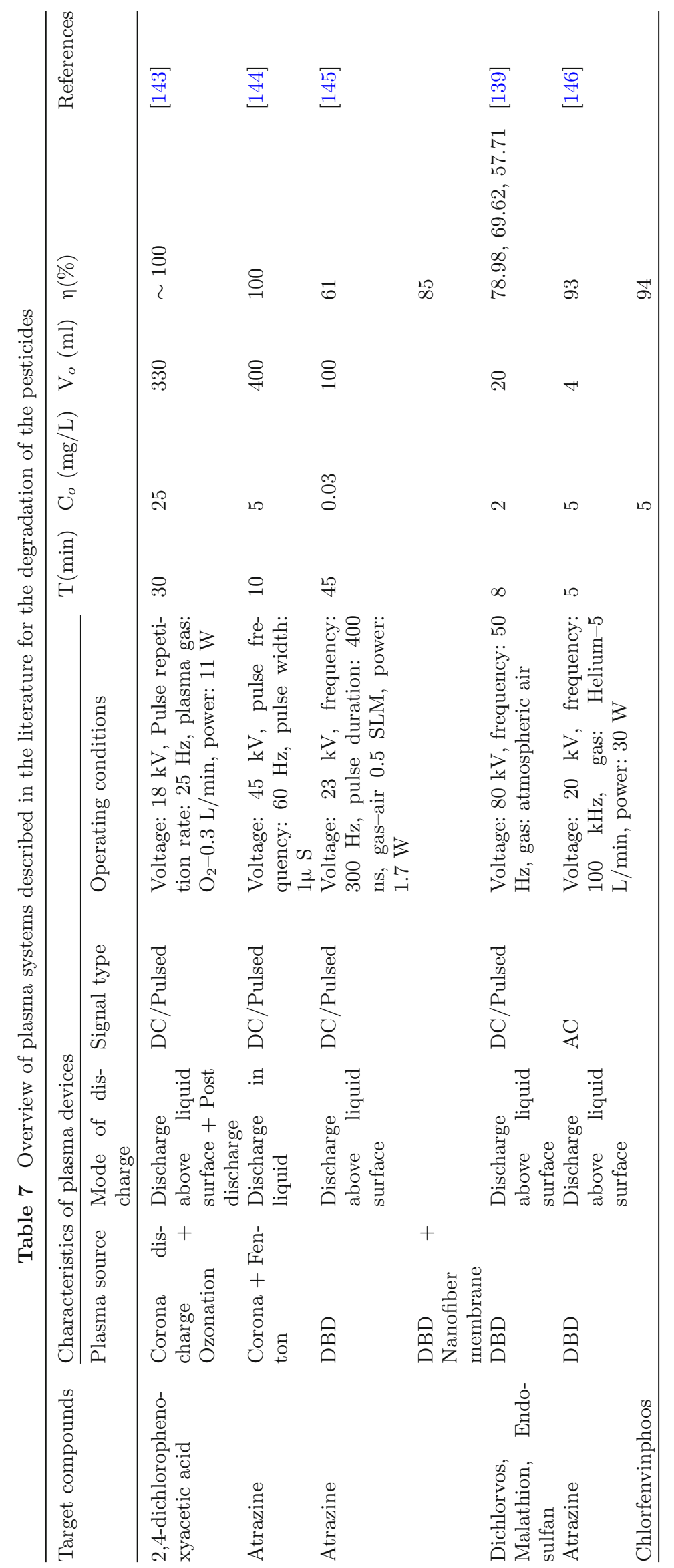




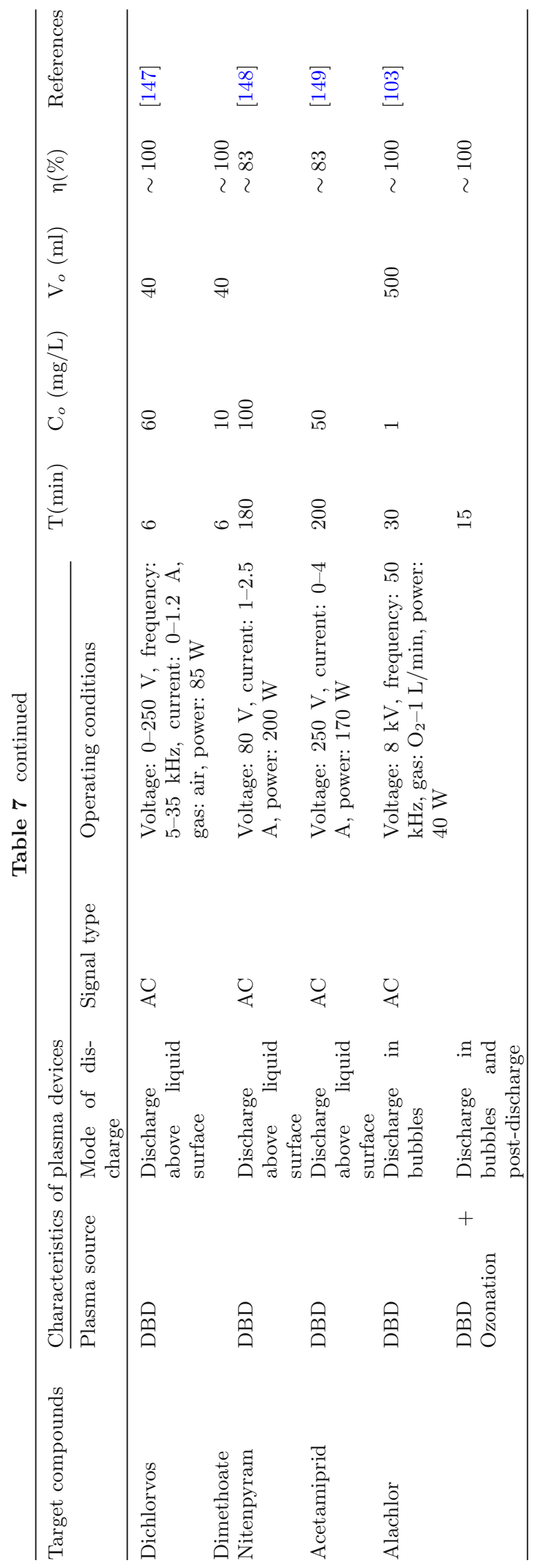


generated hydrogen peroxide. The authors compared processes with a high voltage electrode made of platinum and nickel-chromium and observed that degradation was amplified with a platinum type electrode.

Vanraes et al. [145] evaluated the DBD plasmainduced degradation of atrazine in the presence of adsorption nanofiber polyamide membranes. The plasma was generated in dry air above a thick water film which was introduced on the membrane. It was found that degradation was increased with addition of the nanofiber polyamide membrane in comparison to the plasma alone. The main influence of the membrane was to expose the pollutants absorbed on the membrane to the plasma. They identified deethylatrazine and ammelide as by-products in the degradation process. Sarangapani et al. [139] investigated the degradation of three pesticides dichlorvos, malathion, and endosulfan in water in a sealed DBD plasma reactor with two circular plate-type electrodes configuration. The solution containing pesticides was placed in a petriplate in between two electrodes, whereas the plasma was formed in the ambient air above the solution. At fixed applied voltage and treatment time, decomposition rates of pesticides were in the following order: dichlorvos, malathion, endosulfan. The degradation of pesticides was fitted by the first-order kinetics and the rate constant increased with applied voltage. Also, they reported the generation of acidic species in the solution including nitric acid and nitrous acid. Hijosa-Valsero et al. [146] compared the degradation of atrazine, chlorfenvinphos, 2,4-dibromophenol and lindane in the aqueous solutions in a batch type DBD system and in a coaxial thin falling water film reactor with noble gas helium as a working gas in both types of reactors. In the case of the DBD batch reactor, a solution containing a petri dish was placed in two Pyrex glass containers (served as dielectric barriers). When high voltage was applied to the electrode the discharge takes place in gas in contact with the sample. In a coaxial thin-film DBD reactor, a copper mesh type of electrode was used as a high voltage electrode and it was wrapped over the glass vessel (served as a dielectric barrier). A stainless steel tube acted as a grounded electrode was situated at the vessel's axial center. The solution was introduced from the top and wetted surface was formed on the tube. The discharge occurs in helium over the thin falling film. The degradation followed the first-order kinetics for both reactors and the degradation rate of all pollutants was faster in the batch type DBD reactor. Reddy et al. [102] studied the degradation of pesticide endosulfan in an aqueous solution in a combination of a DBD plasma and a cerium oxide catalyst. The plasma occurred inside the solution when air as a working gas was bubbled through the sample. They claimed that the addition of catalyst showed better degradation performance than plasma alone and the enhancement of degradation of endosulfan in the aqueous solution was attributed to the catalyst-induced decomposition of ozone into atomic oxygen species. They reported fitting of the first-order degradation kinetics on both treatment conditions (plasma - catalyst and plasma alone).
$\mathrm{Hu}$ et al. [147] demonstrated the degradation of dichlorvos and dimethoate in wastewater by utilizing DBD plasma formed in the air over the solution. It was found that the reduction of the discharge gap had a significant positive effect on degradation due to formation of a stronger electric field and hence higher concentrations of reactive species. On the other hand, the addition of hydroxyl radical scavenger (tertbutyl alcohol) had an adverse effect on the degradation of both pesticides, demonstrating that hydroxyl radicals were the main species responsible for degradation. The degradation kinetics of both compounds were a combination of the zeroth and first-order. An unusual DBD plasma reactor has been evaluated by Li et al. [148] for the treatment of a solution containing nitenpyram, where the plasma was created in ambient air above the sample. The reactor consists of a radial-flow sedimentation tank, with a high-voltage electrode situated on top of the tank above the quartz glass while the ground electrode was a wire inserted in the center of the tank, inside the liquid. The solution was recirculated continuously during plasma treatments. They studied a series of parameters that influence the degradation, including initial $\mathrm{pH}$, the addition of catalysts $\left(\mathrm{FeSO}_{4}\right.$, $\mathrm{Fe}_{2}\left(\mathrm{SO}_{4}\right)_{3}$ and $\left.\mathrm{MnO}_{2}\right)$, solution conductivity, plasma power, and so on. The degradation rate was improved by the addition of the catalysts. Apart from this, higher $\mathrm{pH}$, lower conductivity and higher power supplied to plasma favored faster degradation process. Li et al. [149] used the same DBD plasma reactor configuration for the decomposition of acetamiprid in wastewater. They tested the effect of a radical scavenger $\left(\mathrm{Na}_{2} \mathrm{~B}_{4} \mathrm{O}_{7}\right)$ on the degradation and showed that it was inhibited by the addition of $\mathrm{Na}_{2} \mathrm{~B}_{4} \mathrm{O}_{7}$. Recently, Wardenier et al. [103] used a pulsed DBD plasma reactor coupled with activated carbon and ozonator for the elimination of pesticide alachlor. The experiments were performed in two different modes of operation of the sample flow, batch recirculation and single-pass. The oxygen was used as a working gas. They concluded that faster removal of alachlor was achieved during the plasma-ozonation in the batch recirculation type reactor configuration.

\section{Discussion}

A broad range of cold plasma systems with different reactor configurations and operational parameters have been employed and evaluated for the removal of OMPs. In general, the majority of analyzed studies use gasphase plasma established above liquid samples in air or air mixtures with other working gases. Volumes of samples processed in the experiments range from $1 \mathrm{ml}$ to $1000 \mathrm{ml}$. Types of plasma sources present in the literature and used in the decontamination processes of the pesticides, pharmaceuticals and dyes are corona, APPJs, DBDs, etc. [73,74,97,116,122,143]. Of course, this list is much longer, but we tried to limit the types of plasma sources that will be discussed to the ones most commonly used. The corona discharges usually 
have pin pin-to-pin, pin-to-plate or multi-pin configurations and are powered predominantly with pulsed signals $[94,113,142]$. They can operate in the gas phase where the powered electrode is above the treated solution or in liquid phase. In liquid phase powered electrode is inside the treated solution and the plasma is formed inside the bubbles or directly in liquid. The pin electrode configuration is needed in order to obtain the high electric field to ignite the discharge $[71,72,91]$. The drawback associated with single pin electrode type configuration is the generation of lower plasma volume. To enlarge the reaction zone multi-pin electrodes were studied that can lead to the treatment of larger quantity of contaminated water in a shorter period of time.

Similar issues can be found when using the APPJs for decontamination of water. The APPJs have plasma confined in the small volumes and only adding more APPJs will lead to the treatments of larger volumes of contaminated water. Geometry of the APPJs will also influence the efficiency of the treatments. With pinAPPJ (powered electrode is pin type) lower applied powers will be needed for sustaining the discharge (larger electric field at the tip) if compared with the DBD type of APPJ (electrodes wrapped around the glass tube). Another way how to improve the plasma treatment, especially in the case of pin type plasma systems, is to increase the plasma-solution interaction volume through geometries that involve discharges over the falling film $[125,130,146]$ or recirculation of the treated solution $[105,128]$. With DBDs that have parallel electrode system this issue is addressed to some extent. In this case the plasma-liquid interaction surface is larger, but again, if the volume of the treated solution is significant this can hinder the final outcome. In this case the recirculation of the treated solution or treatment of large area of thin layer of solution will increase the transfer of the reactive species from the plasma to the bulk of the solution and increase the efficiency.

Pulsed DC corona and DBD plasma over the thin water film are considered most efficient in the degradation of OMPs $[71,109,125,127,130]$ with the efficiencies going to $100 \%$. Higher mass transfer of reaction species from gas to bulk phase with molecular diffusion along with the plasma discharge leads to faster degradation of OMPs $[69,150,151]$. The thin water film offers a larger surface to volume ratio than other configurations. The bigger plasma-solution contact surface means higher residence time, hence, more interaction of reactive species with the solution for oxidation reaction $[152,153]$. Another way to increase the contact surface is the pulsed corona discharge with a wetted-wall type reactor and coaxial geometry $[125,128]$. It was observed that plasma reactors with continuously mixed solutions have better performance $[109,143,154]$.

In most cases present in the literature, during the treatments discharges are in contact with water or operating in water. Apart from the configurations where short- and long-lived reactive species created in the plasma are in direct contact with the contaminated solution, there are also examples where only long-lived species created in plasma are responsible for the degradation of pollutants $[30,108,115,118]$. In these cases the short-lived radicals, ions and UV emission are not involved in the processes of degradation. For example, Rahimpour et al. [115] used DBD reactor for the treatment of crystal violet dye, where oxygen was used as a feed gas, and the plasma effluents (e.g. ozone) were bubbled in the solution column. In another study by Jiang et al. [118], plasma discharge occurred in the bubble in the liquid solution, where oxygen was used as a feed gas. In this case, the plasma effluent along with treated methyl orange solution passed through the tube and finally bubbled in the reservoir (outside of the plasma reactor). The post-discharge configuration was more favorable than other operation methods for dye treatment. It provides a large interfacial area that leads to an increase in mass transfer between the gas phase and the liquid phase.

Cold atmospheric plasmas are generated by using various feed gases, but mostly by using noble gases (e.g. argon and helium) with the combination of pure molecular gases and/or air (e.g. oxygen and nitrogen) $[72,119]$. Argon and helium have lower breakdown voltage potential characteristics at atmospheric pressure. Therefore, due to the addition of argon and helium with other working gases, the lower voltage can effectively ignite and produce stable plasma discharge and to improve the formation of reactive species. Since they are usually sustained in air the nitrogen-based species are formed and transferred to the solution that can lead to lower $\mathrm{pH}$ value of the solution and increased electrical conductivity [113]. From several experimental studies, it has been found that the presence of pure oxygen in the feed promotes faster OMPs degradation due to the production of the greater amounts of short and longliving reactive oxygen species $[71,74,155]$. The negative side of using the noble gases (especially helium) is their price and need for a more complex system for decontamination. One of the solution is to use the cheaper working gas (for example Ar) and to recirculate it within the system $[30,156]$.

We can see that direct comparison of the different types of plasma devices is not straightforward. Too many parameters are influencing the efficiency of the decontamination and it does not depend only on the type of the plasma device used. Of course, with increase of the power deposited to the discharge one can achieve higher decontamination efficiency regardless of the device type $[101,108]$ Corona discharges have the advantage of not using the additional working gas (APPJs and DBD plasma systems mostly use them). But the corona pin type discharges are usually low volume discharges. As we mentioned above that is a setback that can be overcome. Similarly with the APPJs if one uses recirculation of the working gas (for example $\mathrm{Ar}$ ) the efficiency is obtained and the overall price is still manageable. All of these issues need to be addressed in order to be able to upscale the plasma systems in order to use them in large installations. Unfortunately, there is no definite conclusion which type of plasma device is the most efficient one especially when we take 
into account the type of the pollutant that needs to be decontaminated.

The same experimental conditions different compounds show different treatment results, which revealed that each target compound behaves differently when they come in contact with the plasma [10,30,117,157]. The authors reported that the same plasma device cannot degrade various OMPs to the same extent, therefore different compounds demand different plasma conditions for degradation. Attri et al. [116] have noticed different degradation results at the same experimental condition during the treatment with three organic dyes (methylene blue, methyl orange and congo red dyes) by using argon APPJ. A study conducted by Banaschik et al. [128], where 7 different pharmaceuticals (carbamazepine, diatrizoate, diazepam, diclofenac, ibuprofen, 17a-ethinylestradiol, trimethoprim) were treated by pulsed corona discharge, while plasma occurs directly in aqueous solution. It was found that diclofenac and ethinylestradiol were almost completely degraded, whereas other compounds were not destroyed completely at the same plasma conditions. It was claimed that reactivity between compound and ozone was significantly slow. In the case of pesticides, almost the same dissimilarity is obtained between different pollutants while treatment with the same plasma conditions [139]. Degradation depends on the nature of compounds (e.g. functional group, molecular structure, etc.). Some persistent organic compounds are not very responsive to all plasma-generated reactive species $\left(\mathrm{H}_{2} \mathrm{O}_{2}, \mathrm{O}_{3}\right.$, etc) due to their chemical stability $[30,69,128]$. Some pollutants are hydrophobic and they accumulate at the surface which leads to an increase in their concentration compared to average bulk concentration $[91,157]$. In this case proper mixing is required in order to transfer the reactive species into the bulk liquid and to avoid the consumption of reactive species by pollutants at the surface. In such cases, plasma reactor with a configuration where reactive species generated over large surfaces (e.g. thin falling film with continuous recirculation) could be more efficient for degradation [125,127].

The presence of impurities in the water sample can diminish the interaction of plasma-produced reactive species and target molecules in the liquid. For example, higher degradation of OMPs were observed in pure water than tap water and other water samples with impurities $[94,136]$. This effect is due to the interaction between plasma generated chemically active species with minerals and some organic substances present in tap water. Lower solution $\mathrm{pH}$ (acidic conditions) and lower electrical conductivity of the sample seem to enhance the decomposition of most pollutants due to the faster reactivity of reactive oxygen species in such a liquid environment $[105,148]$. However, a decreased $\mathrm{pH}$ is often not desirable in environmental applications. The effect of increased solution temperature was shown to have a positive influence on the degradation [113] due to the faster reactivity of plasma-generated reactive species.

When it comes to chemical kinetics and decomposition rates, general degradation of OMPs in most of the experiments followed the first-order kinetic model with different applied voltage, plasma power, initial pollutant concentration [90,108, 129, 147]. Additionally, a few zero-order degradation kinetics have also been present in the case of the treatment of dichlorvos and dimethoate by DBD plasma where the air plasma was formed over the solution [147]. The first-order rate kinetics indicates that the degradation of OMPs is directly proportional to the initial concentration of OMPs. On the other hand, the zero-order kinetics means that the degradation of OMPs is independent of the initial concentration of OMPs. Generally, zeroorder kinetics occurs where all reactive species react with OMPs, especially at a higher initial concentration.

Degradation pathways were analyzed by many authors using various tools such as liquid or gas chromatography coupled to mass spectrometry (LCMS, GC-MS) and nuclear magnetic resonance spectroscopy (NMR) enabling identification of typically several transformations products [45,134,142]. Generally, such studies show similar degradation patterns obtained with plasma treatment in comparison to the other oxidative water treatment processes. Unlike other oxidation processes, the study of transformation byproducts provided also evidence for reductive pathway occurrence in plasma treatments, which is an uncommon and potentially useful feature of plasma-driven degradation processes [142]. For example, reductive processes can contribute to the degradation of perfluorinated compounds, a group of compounds of major environmental and human health concern [158].

A synergetic combination of heterogeneous catalysts and plasma reactors has been proposed as another innovative approach and recommended for efficient OMPs degradation $[114,148]$. In all synergetic experimental setups, adding the catalyst had a beneficial effect on the efficiency of the decomposition process. The most commonly used catalyst with a combination of plasma reactors are $\mathrm{TiO}_{2}$ nanoparticles, and these systems showed better performances than systems with plasma only. The increased decomposition with the addition of $\mathrm{TiO}_{2}$ catalyst in the solution is ascribed to the formation of hydroxyl radicals due to photocatalytic reactions on the surface of $\mathrm{TiO}_{2}$ in the presence of plasma generated ultraviolet radiation. Therefore, the degradation of OMPs can be significantly improved by the addition of $\mathrm{TiO}_{2}$. On the other hand, there a few drawbacks associated with catalyst implementation. For example, if the catalysts are added in the form of a slurry then the separation step must be needed to remove them from the treated water for safety concerns.

The energy yield is an important, but complex factor in cold plasma-based wastewater treatment and it depends on several factors (applied power, geometry of the plasma device, plasma volume/surface, working gas that is used etc.). The energy yield is mostly expressed in milligrams or grams/kilowatt-hour ( $\mathrm{mg}$ or $\mathrm{g} / \mathrm{kWh}$ ) and represents the energy ( $\mathrm{kWh}$ ) needed to effectively eliminate the amount of ( $\mathrm{mg}$ or $\mathrm{g}$ ) of OMPs from water [118]. Unfortunately, not all the papers published on the plasma decontamination have reported the energy 
yields or data necessary to calculate this value. Generally, various authors suggest that a higher energy yields were obtained with pulsed corona and pulsed DBD plasma when discharge takes place in oxygen at the gas-liquid interface $[30,71,115,118,122,143]$. Based on the covered literature and available data, the energy yields for cold plasma-based wastewater treatment systems are in the range of $1 \mathrm{mg} / \mathrm{kWh}-12.24 \mathrm{~g} / \mathrm{kWh}$ for organic dyes, $0.13 \mathrm{mg} / \mathrm{kWh}-105 \mathrm{~g} / \mathrm{kWh}$ for pharmaceuticals and $1.22 \mathrm{mg} / \mathrm{kWh}-5.1 \mathrm{~g} / \mathrm{kWh}$ for pesticides.

\section{Conclusions}

Cold plasma technology-based AOPs is a fast emerging field of research aiming to eliminate a wide variety of non-biodegradable OMPs from water. In this article, we reviewed various types of cold atmospheric plasma devices with different operating parameters employed for the degradation of different OMPs (organic dyes, pharmaceuticals, and pesticides) in wastewater. It was found that many parameters can influence degradation, including plasma source, reactor configuration, plasma gas, type of discharge, target compound, and so on. Since many different experimental setups are exploiting a variety of plasma sources, for proper comparison one needs to involve plasma, sample and treatment characteristics.

Overall, it is evident from previous investigations that the cold atmospheric plasma systems showed the potential and innovative route for an effective degradation and complete mineralization of OMPs which cannot successfully be removed by conventional treatment methods. A specifically distinctive feature of plasma chemistry is that simultaneously oxidative and reductive contaminant transformation processes can occur. Therefore, treatment with cold plasma could be an attractive, valuable, and versatile tool for future applications of OMPs removal from wastewater.

However, the authors would like to highlight that there was a lack of information in the majority of papers related to experimental parameters, such as the exact amount of power consumption in order to generate the plasma, sample volume, initial solution $\mathrm{pH}$, solution conductivity, solution temperature, etc. These parameters can have a significant effect on the degradation of OMPs. Specifically, they are needed to assess thoroughly decontamination process performance beyond simple criteria such as the degree of removal achieved. Widely accepted parameter suitable for comparing between different wastewater treatment methods, the energy efficiency, in the case of plasma treatment is not only the function of plasma sources and reactor configurations but it is also dependent on the electrical property of the sample. This entanglement hinders the straight-forward calculation of the parameter and therefore energy efficiency of the plasma sources could not be discussed in this paper. Apart from this, there are several other factors influencing the efficiency of the plasma process, including types of pollutants, chemical structure, concentration, initial $\mathrm{pH}$, the ability of the water matrix to scavenge reactive species, mode of discharge, working gases, applied voltage characteristics, etc. We hence would like to conclude that for the field of wastewater treatment with plasma to further evolve and allow for objective comparisons, a more methodological approach to the characterization of experimental systems should be developed.

Acknowledgements This work was carried out within project NOWELTIES. NOWELTIES received funding from the European Union's Horizon 2020 research and innovation programme under the Marie Skłodowska-Curie grant agreement No. 812880 . N.S. and N.P. are funded by Ministry of Education, Science and Technological Development, grant number 451-03-68/2020-14/200024. This article is based upon work from COST Action PLAGRI - CA19110, supported by COST (European Cooperation in Science and Technology), www.cost.eu.

\section{Author contributions}

Conceptualization N.P., W.G, N.S; literature survey A.K.; writing - original draft preparation, review and editing A.K., N.S., N.P, W.G.; supervision, N.P., W.G.; project administration, N.P., W.G.. All authors have read and agreed to the published version of the manuscript.

Data Availability Statement This manuscript has associated data in a data repository [Authors comment: The data that support the findings of this study are available from the corresponding author upon reasonable request.]

Open Access This article is licensed under a Creative Commons Attribution 4.0 International License, which permits use, sharing, adaptation, distribution and reproduction in any medium or format, as long as you give appropriate credit to the original author(s) and the source, provide a link to the Creative Commons licence, and indicate if changes were made. The images or other third party material in this article are included in the article's Creative Commons licence, unless indicated otherwise in a credit line to the material. If material is not included in the article's Creative Commons licence and your intended use is not permitted by statutory regulation or exceeds the permitted use, you will need to obtain permission directly from the copyright holder. To view a copy of this licence, visit http://creativecomm ons.org/licenses/by/4.0/.

\section{References}

1. S. Khalifa, M. Bidaisee, Sch. J. Appl. Sci. Res. 1, 17 (2018)

2. F. Mugagga, B.B. Nabaasa, Int. Soil Water Conserv. Res. 4, 215 (2016)

3. S. Naidoo, A. Olaniran, Int. J. Environ. Res. Public Health 11, 249 (2013) 
4. A. Jelić, M. Gros, M. Petrović, A. Ginebreda, D. Barceló, Emerg. Prior. Pollut. Rivers. 19, 1 (2012)

5. Y. Luo, W. Guo, H.H. Ngo, L.D. Nghiem, F.I. Hai, J. Zhang, S. Liang, X.C. Wang, Sci. Total Environ. 473474, 619 (2014)

6. L. Sbardella, I. Velo-Gala, J. Comas, I. RodríguezRoda Layret, A. Fenu, and W. Gernjak, J. Hazard. Mater. 380, 120869 (2019)

7. L. Rizzo, S. Malato, D. Antakyali, V. G. Beretsou, M. B. Dolić, W. Gernjak, E. Heath, I. Ivancev-Tumbas, P. Karaolia, A. R. Lado Ribeiro, G. Mascolo, C. S. McArdell, H. Schaar, A. M. T. Silva, D. FattaKassinos, Sci. Total Environ. 655, 986 (2019)

8. V. Katheresan, J. Kansedo, S.Y. Lau, J. Environ. Chem. Eng. 6, 4676 (2018)

9. N. Pathak, V.H. Tran, A. Merenda, M.A.H. Johir, S. Phuntsho, H. Shon, Appl. Sci. 10, 2969 (2020)

10. M. Magureanu, N.B. Mandache, V.I. Parvulescu, Water Res. 81, 124 (2015)

11. E. Forgacs, T. Cserháti, G. Oros, Environ. Int. 30, 953 (2004)

12. E. Routoula, S.V. Patwardhan, Environ. Sci. Technol. 54, 647 (2020)

13. T.A. Nguyen, R.-S. Juang, Chem. Eng. J. 219, 109 (2013)

14. S. Benkhaya, S. Mrabet, A. El Harfi, Inorg. Chem. Commun. 115, 107891 (2020)

15. N. Wardenier, Non-Equilibrium plasma in contact with water as advanced oxidation process for decomposition of micropollutants, Masters dissertation, Ghent University, 2016

16. P. Schröder, B. Helmreich, B. Škrbić, M. Carballa, M. Papa, C. Pastore, Z. Emre, A. Oehmen, A. Langenhoff, M. Molinos, J. Dvarioniene, C. Huber, K.P. Tsagarakis, E. Martinez-Lopez, S.M. Pagano, C. Vogelsang, G. Mascolo, Environ. Sci. Pollut. Res. 23, 12835 (2016)

17. C.S. Leal, D.P. Mesquita, A.L. Amaral, A.M. Amaral, E.C. Ferreira, Crit. Rev. Environ. Sci. Technol. 50, 698 (2020)

18. M.J. Ahmed, J. Environ. Manage. 190, 274 (2017)

19. A. Bayer, R. Asner, W. Schüssler, W. Kopf, K. Weiß, M. Sengl, M. Letzel, Environ. Sci. Pollut. Res. 21, $10830(2014)$

20. A. Lajeunesse, S.A. Smyth, K. Barclay, S. Sauvé, C. Gagnon, Water Res. 46, 5600 (2012)

21. H. He, Y. Liu, S. You, J. Liu, H. Xiao, Z. Tu, Int. J. Environ. Res. Public Health 16, 5129 (2019)

22. N. Stamatis, D. Hela, I. Konstantinou, J. Hazard. Mater. 175, 829 (2010)

23. T. Ahmad, M. Rafatullah, A. Ghazali, O. Sulaiman, R. Hashim, A. Ahmad, J. Environ. Sci. Heal. Part C 28, 231 (2010)

24. J. Regnery, P. Parrhysius, R.S. Schulz, C. Möhlenkamp, G. Buchmeier, G. Reifferscheid, M. Brinke, Water Res. 167, 115090 (2019)

25. W.-Q. Han, L.-J. Wang, X.-Y. Sun, J.-S. Li, J. Hazard. Mater. 151, 306 (2008)

26. R. Katal, H. Zare, S.O. Rastegar, P. Mavaddat, G.N. Darzi, Environ. Eng. Manag. J. 13, 43 (2014)

27. W. Zheng, X. Li, Z. Hao, D. Wang, Q. Yang, G. Zeng, Water Sci. Technol. 62, 15 (2010)
28. N. Misra, R. Satyanarayan, S. Potle, Int. J. Chem. Phys. Sci. 2, 39-51 (2013)

29. E.M. Cuerda-Correa, M.F. Alexandre-Franco, C. Fernández-González, Water 12, 102 (2019)

30. M. Hijosa-Valsero, R. Molina, A. Montràs, M. Müller, J.M. Bayona, Environ. Technol. Rev. 3, 71 (2014)

31. P.R. Gogate, A.B. Pandit, Adv. Environ. Res. 8, 553 (2004)

32. P.R. Gogate, A.B. Pandit, Adv. Environ. Res. 8, 501 (2004)

33. O. Legrini, E. Oliveros, A.M. Braun, Chem. Rev. 93, 671 (1993)

34. A.S. Stasinakis, Glob. NEST J. 10, 376 (2008)

35. Z. L. Makabe, T., \& Petrovic, Plasma electronics: applications in microelectronic device fabrication (Vol. 26), (CRC Press, 2014)

36. F.F. Chen, Introduction to plasma physics and controlled fusion, 3rd edn. (Springer, Cham, 2016)

37. M.A. Lieberman, A.J. Lichtenberg, Principles of plasma discharges and materials processing, 2nd edn. (Wiley, Hoboken, NJ, USA, 2005)

38. A. Fridman, Plasma chemistry, 1st edn. (Cambridge University Press, Cambridge, 2008)

39. P. Bruggeman, R. Brandenburg, J. Phys. D. Appl. Phys. 46, 464001 (2013)

40. A. Schutze, J.Y. Jeong, S.E. Babayan, J. Park, G.S. Selwyn, R.F. Hicks, IEEE Trans. Plasma Sci. 26, 1685 (1998)

41. C. Tendero, C. Tixier, P. Tristant, J. Desmaison, P. Leprince, Spectrochim. Acta Part B. At. Spectrosc. 61, 2 (2006)

42. J.E. Foster, Phys. Plasmas 24, 055501 (2017)

43. P.J. Bruggeman, F. Iza, R. Brandenburg, Plasma Sour. Sci. Technol. 26, 123002 (2017)

44. J. Ananthanarasimhan, R. Lakshminarayana, M.S. Anand, S. Dasappa, Plasma Sources Sci. Technol. 28, 085012 (2019)

45. L. Wu, Q. Xie, Y. Lv, Z. Wu, X. Liang, M. Lu, Y. Nie, Water 11, 1815 (2019)

46. S. Gopi, A. Sarma, A. Patel, G. Ravi, Instrum. Sci. Technol. 41, 651 (2013)

47. F. Rezaei, P. Vanraes, A. Nikiforov, R. Morent, N. De Geyter, Mater. (Basel). 12, 2751 (2019)

48. A.K. Jaiswal, J. Ananthanarasimhan, A.M. Shivapuji, S. Dasappa, L. Rao, J. Phys. D. Appl. Phys. 53, 465205 (2020)

49. A.M. Ali, M.A.A. Hassan, B.I. Abdulkarim, IOSR. J. Environ. Sci. 10, 63 (2016)

50. P. Favia, G. Cicala, A. Milella, F. Palumbo, P. Rossini, R. D-Agostino, Surf. Coatings Technol. 169-170, 609 (2003)

51. E.E. Kunhardt, IEEE Trans. Plasma Sci. 28, 189 (2000)

52. J.R. Roth, Industrial plasma engineering, 1st edn. (CRC Press, Florida, 1995)

53. M. Gorenšek, M. Gorjanc, V. Bukošek, J. Kovač, Z. Petrović, N. Puač, Text. Res. J. 80, 1633 (2010)

54. D. Mance, R. Wiese, T. Kewitz, H. Kersten, Eur. Phys. J. D 72, 98 (2018)

55. S. Živković, N. Puač, Z. Giba, D. Grubišić, Z.L. Petrović, Seed Sci. Technol. 32, 693 (2004)

56. J. Heinlin, G. Morfill, M. Landthaler, W. Stolz, G. Isbary, J.L. Zimmermann, T. Shimizu, S. Karrer, 
J.D.D.G.J. Der Dtsch, Dermatologischen Gesellschaft 8, 968 (2010)

57. D. Mariotti, T. Belmonte, J. Benedikt, T. Velusamy, G. Jain, V. Švrček, Plasma Process. Polym. 13, 70 (2016)

58. N. Puač, M. Gherardi, M. Shiratani, Plasma Process. Polym. 15, 1700174 (2018)

59. N. Puač, Z.L. Petrović, G. Malović, A. Dordević, S. Živković, Z. Giba, D. Grubišić, J. Phys. D. Appl. Phys. 39, 3514 (2006)

60. J. Winter, R. Brandenburg, K.-D. Weltmann, Plasma Sour. Sci. Technol. 24, 064001 (2015)

61. J. Peran \& S. Ercegović Ražić, Text. Res. J. 90, 1174 (2020)

62. A. Zille, F.R. Oliveira, A.P. Souto, Plasma Process. Polym. 12, 98 (2015)

63. C. Bradu, K. Kutasi, M. Magureanu, N. Puač, S. Živković, J. Phys. D. Appl. Phys. 53, 223001 (2020)

64. T. von Woedtke, S. Reuter, K. Masur, K.-D. Weltmann, Phys. Rep. 530, 291 (2013)

65. M.G. Kong, G. Kroesen, G. Morfill, T. Nosenko, T. Shimizu, J. van Dijk, J.L. Zimmermann, New J. Phys. 11, 115012 (2009)

66. V.I. Parvulescu, M. Magureanu, P. Lukes, Plasma chemistry and catalysis in gases and liquids, 1st edn. (Wiley, New York, 2012)

67. N. Škoro, D. Marić, G. Malović, W.G. Graham, Z.L. Petrović, Phys. Rev. E 84, 055401 (2011)

68. L. Bárdos, H. Baránková, Thin Solid Films 518, 6705 (2010)

69. B. Jiang, J. Zheng, S. Qiu, M. Wu, Q. Zhang, Z. Yan, Q. Xue, Chem. Eng. J. 236, 348 (2014)

70. J. Zhang, J. Chen, X. Li, J. Water Resour. Prot. 01, 99 (2009)

71. M.A. Malik, Plasma Chem. Plasma Process. 30, 21 (2010)

72. P. Vanraes, A. Y. Nikiforov, and C. Leys, in Plasma Sci. Technol. - Prog. Phys. States Chem. React. (InTech, 2016)

73. D. He, Y. Sun, L. Xin, J. Feng, Chem. Eng. J. 258, 18 (2014)

74. M. Magureanu, D. Piroi, F. Gherendi, N.B. Mandache, V. Parvulescu, Plasma Chem. Plasma Process. 28, 677 (2008)

75. N. Škoro, N. Puač, S. Živković, D. Krstić-Milošević, U. Cvelbar, G. Malović, Z.L. Petrović, Eur. Phys. J. D 72, 2 (2018)

76. P. Lukes, E. Dolezalova, I. Sisrova, M. Clupek, Plasma Sources Sci. Technol. 23, 015019 (2014)

77. R. Zhou, T. Zhang, R. Zhou, A. Mai-Prochnow, S.B. Ponraj, Z. Fang, H. Masood, J. Kananagh, D. McClure, D. Alam, K. Ostrikov, P.J. Cullen, Sci. Total Environ. 750, 142295 (2021)

78. N. Puač, M. Miletić, M. Mojović, A. Popović-Bijelić, D. Vuković, B. Miličić, D. Maletić, S. Lazović, G. Malović, Z.L. Petrović, Open Chem. 13, 332 (2014)

79. P. Bruggeman, C. Leys, J. Phys. D. Appl. Phys. 42, 053001 (2009)

80. J. Du, Z. Liu, C. Bai, L. Li, Y. Zhao, L. Wang, J. Pan, Eur. Phys. J. D 72, 179 (2018)

81. A. Capodaglio, Appl. Sci. 9, 4562 (2019)

82. J. Foster, B.S. Sommers, S.N. Gucker, I.M. Blankson, G. Adamovsky, IEEE Trans. Plasma Sci. 40, 1311 (2012)
83. D. Ghernaout, N. Elboughdiri, OALib 07, 1 (2020)

84. S. M, in Proc. MOL2NET 2018, International Conference on Multidisciplinary Science. 4th Ed. (MDPI, Basel, Switzerland, 2018), p. 5502

85. Y. Cui, J. Cheng, Q. Chen, Z. Yin, I.O.P. Conf, Ser. Earth Environ. Sci. 208(2018)

86. J. Ren, T. Wang, G. Qu, D. Liang, S. Hu, Plasma Sci. Technol. 17, 1053 (2015)

87. C. Sarangapani, D. Ziuzina, P. Behan, D. Boehm, B.F. Gilmore, P.J. Cullen, P. Bourke, Sci. Rep. 9, 1 (2019)

88. M. Markovi, M. Jovi, D. Stankovi, V. Kova, G. Rogli, G. Gojgi, D. Manojlovi, Sci. Total Environ. 505, 1148 (2015)

89. J. Yu, Y. Cui, H. Zhang, Y. Liu, G. Oinuma, Chemosphere 234, 471 (2019)

90. A. Fahmy, A. El-Zomrawy, A. M. Saeed, A. Z Sayed, M. A Ezz El-Arab, H. Shehata, and J. Friedrich, Plasma Res. Express 2, 015009 (2020)

91. B.R. Locke, M. Sato, P. Sunka, M.R. Hoffmann, J.S. Chang, Ind. Eng. Chem. Res. 45, 882 (2006)

92. M. Russo, G. Iervolino, V. Vaiano, V. Palma, Catalysts 10, 1 (2020)

93. A. Barjasteh, Z. Dehghani, P. Lamichhane, N. Kaushik, E.H. Choi, N.K. Kaushik, Appl. Sci. 11, 3372 (2021)

94. M. A. Malik, Ubaid-Ur-Rehman, A. Ghaffar, and K. Ahmed, Plasma Sour. Sci. Technol. 11, 236 (2002)

95. E. Marotta, E. Ceriani, V. Shapoval, M. Schiorlin, C. Ceretta, M. Rea, C. Paradisi, Eur. Phys. J. Appl. Phys. 55, 13811 (2011)

96. M. El Shaer, M. Eldaly, G. Heikal, Y. Sharaf, H. Diab, M. Mobasher, A. Rousseau, Plasma Chem. Plasma Process. 40, 971 (2020)

97. K. H. Hama Aziz, H. Miessner, S. Mueller, D. Kalass, D. Moeller, I. Khorshid, and M. A. M. Rashid, Chem. Eng. J. 313, 1033 (2017)

98. P. J. Bruggeman, M. J. Kushner, B. R. Locke, J. G. E. Gardeniers, W. G. Graham, D. B. Graves, R. C. H. M. Hofman-Caris, D. Maric, J. P. Reid, E. Ceriani, D. Fernandez Rivas, J. E. Foster, S. C. Garrick, Y. Gorbanev, S. Hamaguchi, F. Iza, H. Jablonowski, E. Klimova, J. Kolb, F. Krcma, P. Lukes, Z. Machala, I. Marinov, D. Mariotti, S. Mededovic Thagard, D. Minakata, E. C. Neyts, J. Pawlat, Z. L. Petrovic, R. Pflieger, S. Reuter, D. C. Schram, S. Schröter, M. Shiraiwa, B. Tarabová, P. A. Tsai, J. R. R. Verlet, T. von Woedtke, K. R. Wilson, K. Yasui, and G. Zvereva, Plasma Sources Sci. Technol. 25, 053002 (2016)

99. L. Lin, S.A. Starostin, S. Li, V. Hessel, Phys. Sci. Rev. 3, 1 (2018)

100. Y. Gorbanev, A. Privat-Maldonado, A. Bogaerts, Anal. Chem. 90, 13151 (2018)

101. S. Muradia, Study of low-voltage pulsed plasma discharges inside water using a bubble-generating porous ceramic electrode for wastewater treatment, Doctoral dissertation, Shizuoka University, 2013

102. P. Manoj Kumar Reddy, S. Mahammadunnisa, and C. Subrahmanyam, Chem. Eng. J. 238, 157 (2014)

103. N. Wardenier, Y. Gorbanev, I. Van Moer, A. Nikiforov, S.W.H. Van Hulle, P. Surmont, F. Lynen, C. Leys, A. Bogaerts, P. Vanraes, Water Res. 161, 549 (2019)

104. F. Tampieri, A. Giardina, F.J. Bosi, A. Pavanello, E. Marotta, B. Zaniol, G. Neretti, C. Paradisi, Plasma Process. Polym. 15, 1700207 (2018) 
105. A.T. Sugiarto, T. Ohshima, M. Sato, Thin Solid Films 407, 174 (2002)

106. R. Kant, Nat. Sci. 04, 22 (2012)

107. H. Ghodbane, A.Y. Nikiforov, O. Hamdaoui, P. Surmont, F. Lynen, G. Willems, C. Leys, J. Adv. Oxid. Technol. 17, 372 (2014)

108. Q. Tang, W. Jiang, Y. Zhang, W. Wei, T.M. Lim, Plasma Chem. Plasma Process. 29, 291 (2009)

109. D. Piroi, M. Magureanu, N. B. Mandache, and V. I. Parvulescu, in 19th International Sympsium of Plasma Chemistry (2009), pp. 1-4

110. G. Farabegoli, L. Pletrelli, E. Rolle, A. Sabene, Water Sci. Technol. Water Supply. 4, 65 (2004)

111. I. M. C. Gonçalves*, A. Gomes, R. Brás, M. I. A. Ferra, M. T. P. Amorim, and R. S. Porter, J. Soc. Dye. Colour. 116, 393 (2000)

112. T. Shindhal, P. Rakholiya, S. Varjani, A. Pandey, H.H. Ngo, W. Guo, H.Y. Ng, M.J. Taherzadeh, Bioeng 12, $70(2021)$

113. L. O. B. de Benetoli, B. M. Cadorin, C. Da S. Postiglione, I. G. De Souzaa, and N. A. Debacher, J. Braz. Chem. Soc. 22, 1669 (2011)

114. J. Li, Z. Zhou, H. Wang, G. Li, Y. Wu, Desalin 212, 123 (2007)

115. M. Rahimpour, H. Taghvaei, S. Zafarnak, M.R. Rahimpour, S. Raeissi, J. Environ. Chem. Eng. 7, 103220 (2019)

116. P. Attri, M. Yusupov, J.H. Park, L.P. Lingamdinne, J.R. Koduru, M. Shiratani, E.H. Choi, A. Bogaerts, Sci. Rep. 6, 1 (2016)

117. F. Abdelmalek, M.R. Ghezzar, M. Belhadj, A. Addou, J.L. Brisset, Ind. Eng. Chem. Res. 45, 23 (2006)

118. B. Jiang, J. Zheng, Q. Liu, M. Wu, Chem. Eng. J. 204-205, 32 (2012)

119. B. Sun, N.N. Aye, Z. Gao, D. Lv, X. Zhu, M. Sato, J. Environ. Sci. 24, 840 (2012)

120. I. Panorel, S. Preis, I. Kornev, H. Hatakka, M. LouhiKultanen, Environ. Technol. (United Kingdom) 34, 923 (2013)

121. D.G.J. Larsson, C. de Pedro, N. Paxeus, J. Hazard. Mater. 148, 751 (2007)

122. M. Magureanu, D. Piroi, N.B. Mandache, V. David, A. Medvedovici, C. Bradu, V.I. Parvulescu, Water Res. 45, 3407 (2011)

123. X. Hao, M. Zhou, Q. Xin, L. Lei, Chemosphere 66, 2185 (2007)

124. S. Krishna, A. Maslani, T. Izdebski, M. Horakova, S. Klementova, P. Spatenka, Chemosphere 152, 47 (2016)

125. S. Rong, Y. Sun, J. Chem. Technol. Biotechnol. 89, $1351(2014)$

126. D. Dobrin, C. Bradu, M. Magureanu, N.B. Mandache, V.I. Parvulescu, Chem. Eng. J. 234, 389 (2013)

127. H. Krause, B. Schweiger, J. Schuhmacher, S. Scholl, U. Steinfeld, Chemosphere 75, 163 (2009)

128. R. Banaschik, P. Lukes, H. Jablonowski, M.U. Hammer, K.D. Weltmann, J.F. Kolb, Water Res. 84, 127 (2015)

129. R.K. Singh, L. Philip, S. Ramanujam, Water Res. 121, $20(2017)$

130. C. Hao, Z. Yan, K. Liu, J. Qiu, IEEE Trans. Plasma Sci. 48, 471 (2020)

131. Y. Baloul, D. Hong, S. Chuon, O. Aubry, Int. J. Plasma Environ. Sci. Technol. 10, 102 (2016)
132. M.I. Nawaz, C. Yi, P.J. Asilevi, T. Geng, M. Aleem, A.M. Zafar, A. Azeem, H. Wang, Water. 11, 842 (2019)

133. M. Magureanu, D. Piroi, N.B. Mandache, V. David, A. Medvedovici, V.I. Parvulescu, Water Res. 44, 3445 (2010)

134. J. Smith, I. Adams, H.-F. Ji, Plasma 1, 1 (2017)

135. M. Magureanu, D. Dobrin, N.B. Mandache, C. Bradu, A. Medvedovici, V.I. Parvulescu, Plasma Process. Polym. 10, 459 (2013)

136. L. Gao, L. Sun, S. Wan, Z. Yu, M. Li, Chem. Eng. J. 228, 790 (2013)

137. M. Hijosa-Valsero, R. Molina, H. Schikora, M. Müller, J.M. Bayona, Water Res. 47, 1701 (2013)

138. V. Vasu, D. Raji, A. Pandiyaraj, K.N. Padmanabhan, P.V.A. Kandhavelu, Front. Adv. Mater. Res. 1, $46(2019)$

139. C. Sarangapani, N.N. Misra, V. Milosavljevic, P. Bourke, F. O-Regan, P.J. Cullen, J. Water Process Eng. 9, 225 (2016)

140. A. Székács, M. Mörtl, B. Darvas, J. Chem. 2015, 15 (2015)

141. C. Vanraes, P. Ghodbane, H. Davister, D. Wardenier, N. Nikiforov, A. Verheust, Y.P. Van Hulle, S.W.H. Hamdaoui, O. Vandamme, J. Durme, J.V. Surmont, P. Lynen, F. Leys, Water Res. 116, 1 (2017)

142. R.K. Singh, L. Philip, S. Ramanujam, Ind. Eng. Chem. Res. 55, 7201 (2016)

143. C. Bradu, M. Magureanu, V.I. Parvulescu, J. Hazard. Mater. 336, 52 (2017)

144. S. Mededovic, B.R. Locke, Ind. Eng. Chem. Res. 46, 2702 (2007)

145. P. Vanraes, G. Willems, N. Daels, S.W.H. Van Hulle, K. De Clerck, P. Surmont, F. Lynen, J. Vandamme, J. Van Durme, A. Nikiforov, C. Leys, Water Res. 72, 361 (2015)

146. M. Hijosa-Valsero, R. Molina, H. Schikora, M. Müller, J.M. Bayona, J. Hazard. Mater. 262, 664 (2013)

147. Y. Hu, Y. Bai, H. Yu, C. Zhang, J. Chen, Bull. Environ. Contam. Toxicol. 91, 314 (2013)

148. S.P. Li, Y.Y. Jiang, X.H. Cao, Y.W. Dong, M. Dong, J. Xu, Environ. Technol. (United Kingdom) 34, 1609 (2013)

149. S. Li, X. Ma, Y. Jiang, X. Cao, Ecotoxicol. Environ. Saf. 106, 146 (2014)

150. V.V. Kovačević, B.P. Dojčinović, M. Jović, G.M. Roglić, B.M. Obradović, M.M. Kuraica, J. Phys. D. Appl. Phys. 50, 155205 (2017)

151. S. Mohades, A.M. Lietz, J. Kruszelnicki, M.J. Kushner, Plasma Process. Polym. 17, 1900179 (2020)

152. L. Patinglag, D. Sawtell, A. Iles, L.M. Melling, K.J. Shaw, Plasma Chem. Plasma Process. 39, 561 (2019)

153. O. Lesage, T. Roques-Carmes, J.-M. Commenge, X. Duten, M. Tatoulian, S. Cavadias, D. Mantovani, S. Ognier, Ind. Eng. Chem. Res. 53, 10387 (2014)

154. Z. Kozakova, E.J. Klimova, B.M. Obradovic, B.P. Dojcinovic, F. Krcma, M.M. Kuraica, Z. Olejnickova, R. Sykora, M. Vavrova, Plasma Process. Polym. 15, 1700178 (2018)

155. B.R. Locke, K.-Y. Shih, Plasma Sources Sci. Technol. 20, 034006 (2011)

156. S. Jaiswal, E.M. Aguirre, AIP Adv. 11, 045311 (2021) 
157. S.M. Thagard, G.R. Stratton, F. Dai, C.L. Bellona, T.M. Holsen, D.G. Bohl, E. Paek, E.R.V. Dickenson, J. Phys. D. Appl. Phys. 50, 014003 (2017)
158. R.K. Singh, S. Fernando, S.F. Baygi, N. Multari, S.M. Thagard, T.M. Holsen, Environ. Sci. Technol. 53, 2731 (2019) 